\title{
Negatively controlled, randomized clinical trial to evaluate intramammary treatment of nonsevere, gram-negative clinical mastitis
}

\author{
M. J. Fuenzalida ${ }^{1}$ and P. L. Ruegg ${ }^{2 *}$ \\ ${ }^{1}$ Department of Dairy Science, University of Wisconsin, Madison 53706 \\ ${ }^{2}$ Department of Animal Science, Michigan State University, East Lansing 48864
}

\section{ABSTRACT}

The objective of this negatively controlled, randomized clinical trial was to examine clinical outcomes of 2-d or 8-d treatment using an approved intramammary (IMM) product containing ceftiofur hydrochloride compared with no antimicrobial treatment of nonsevere, gram-negative cases of clinical mastitis (CM). Additionally, we contrasted clinical outcomes of cases caused by Escherichia coli $(\mathrm{n}=56)$ or Klebsiella pneumoniae $(\mathrm{n}=54)$. Cases $(\mathrm{n}=168)$ of nonsevere (abnormal milk or abnormal milk and udder) $\mathrm{CM}$ were randomly assigned to receive $2 \mathrm{~d}(\mathrm{n}=56)$ or $8 \mathrm{~d}(\mathrm{n}=56)$ of IMM ceftiofur or assigned to a negative control group $(\mathrm{n}=$ 56). At enrollment, quarter milk samples were collected and used for on-farm culture, somatic cell count (SCC), and confirmatory microbiological analysis. Quarter milk samples were collected weekly from 7 to $28 \mathrm{~d}$ after enrollment for microbiological and SCC analysis. Clinical outcomes were followed for $90 \mathrm{~d}$ or until the end of lactation (follow-up period, FUP). Overall, no significant differences in quarter-level recurrence of CM $(32 \%$ for negative control, $34 \%$ for the 2 -d treatment, and $32 \%$ for the 8 -d treatment), culling ( $18 \%$ for negative control, $12 \%$ for 2 -d treatment, and $11 \%$ for 8 -d treatment), voluntary dry-off of affected quarters (20\% for negative control, $30 \%$ for 2 -d treatment, and $27 \%$ for 8 -d treatment), days until return to normal milk (4.2 days for negative control, 4.8 days for 2-d treatment, 4.5 days for 8 -d treatment), weekly quarter-SCC during the FUP $\left(6.1,6.3\right.$, and $6.0 \log _{10} \mathrm{SCC}$ for the negative control, 2-d, and 8-d treatments, respectively), or daily milk yield during the FUP $(37.1,36.3$, and $37.6 \mathrm{~kg} / \mathrm{cow}$ per day for the negative control, 2-d, and 8-d treatments, respectively) were observed among experimental groups. Days of discarded milk were greater for cows assigned to 8-d IMM ceftiofur $(11.1 \mathrm{~d})$ than for cows assigned to $2-\mathrm{d}(6.9 \mathrm{~d})$ or cows assigned to negative

Received December 12, 2018.

Accepted February 13, 2019.

*Corresponding author: plruegg@msu.edu control (5.6 d). Bacteriological cure (BC) at 14 and 21 $\mathrm{d}$ after enrollment was greater in cows assigned to 8-d $(89 \%)$ and $2-d(84 \%)$ treatment than in cows assigned to negative control $(67 \%)$, but this outcome was confounded by pathogen. For CM caused by Kleb. pneumoniae, $\mathrm{BC}$ was greater for quarters assigned to receive treatment (combined 2-d and 8-d groups; $74 \% \mathrm{BC}$ ) than for quarters assigned to negative control (18\%). In contrast, no differences in $\mathrm{BC}$ were observed for CM caused by E. coli (97-98\%). Culling and voluntary dry-off of affected quarters were significantly greater for cows with quarters affected by Kleb. pneumoniae (22\% culled, $39 \%$ voluntary dry-off of quarters) than for cows with quarters affected with $E$. coli ( $7 \%$ culled, $11 \%$ voluntary dry-off of quarters). Overall, use of IMM ceftiofur did not result in improvement of most clinical outcomes, but differences between E. coli and Kleb. pneumoniae were evident. In contrast to E. coli, Kleb. pneumoniae caused chronic intramammary infection and induced worse clinical outcomes. Intramammary antibiotic treatment of most mild and moderate cases of CM caused by E. coli is not necessary, but more research is needed to identify which quarters affected by Kleb. pneumoniae may benefit from antimicrobial therapy.

Key words: dairy cow, clinical mastitis, antimicrobial, gram-negative

\section{INTRODUCTION}

Clinical mastitis (CM) is the most common reason that dairy cows receive intramammary (IMM) antibiotics (USDA, 2014), and the majority of IMM treatments are not targeted based on etiology (Oliveira et al., 2013). Nonspecific use of antibiotics on farms has led some to believe that antibiotics are misused, and consumers and regulators often associate use of antimicrobials on farms with increasing antimicrobial resistance (Sifferlin, 2017). An association between increased risk of antimicrobial resistance of non-aureus staphylococci and systemic administration of some antimicrobials has been recently described (Nobrega et 
al., 2018). However, a linkage between IMM usage of antimicrobials and development of resistance has not yet been substantiated (Erskine et al., 2002; Makovec and Ruegg, 2003; Nobrega et al., 2018). Use of culturebased, selective treatment protocols for CM can reduce use of antimicrobials for cases that are culture negative or gram negative (Lago et al., 2011 a,b; Vasquez et al., 2017; Fuenzalida and Ruegg, 2019). However, among gram-negative bacteria causing IMI, severity of the inflammatory response and outcomes of antimicrobial treatment may vary (Oliveira et al., 2013).

Cases of CM can be categorized based on magnitude of inflammation, with nonsevere cases defined as including mild (abnormal milk only) and moderate cases (abnormal milk accompanied with local signs in the udder). In the United States, the majority of cows affected with nonsevere $\mathrm{CM}$ receive nonspecific treatment with approved IMM antimicrobials (USDA, 2014). A study of mastitis occurring on larger Wisconsin dairy herds demonstrated that gram-negative bacteria caused about $36 \%$ of CM, with Escherichia coli (22\%) and Klebsiella spp. (7\%) as the most prevalent pathogens (Oliveira et al., 2013). Most gram-negative bacteria preferentially colonize superficial mucosal surfaces within the mammary gland and induce an acute immune response with a pronounced inflammatory response (Bannerman et al., 2004a,b). Cases of CM caused by E. coli are usually characterized by a short duration based on stimulation of a rapid and effective immune response (Smith et al., 1985; Pyörälä et al., 1994; Bannerman et al., 2004a,b). In contrast, CM caused by Klebsiella spp. has been characterized by a longer subclinical phase (Todhunter et al., 1991), greater risk of culling (Gröhn et al., 2005), and less-successful clinical outcomes (Oliveira et al., 2013). Schukken et al. (2011) reported a large advantage in bacteriological cure (BC) of CM cases caused by E. coli and Klebsiella spp. that were treated with 5-d IMM ceftiofur, compared with nontreated controls, but did not detect differences in important clinical outcomes such as post-treatment milk yield or culling. Suojala et al. (2010) found no differences in BC or any relevant economic trait of $\mathrm{CM}$ caused by $E$. coli that received a combination of systemic enrofloxacin and the nonsteroidal anti-inflammatory ketoprofen compared to cases that only received ketoprofen. Mastitis caused by E. coli and Klebsiella spp. vary in pathogenicity (Schukken et al., 2012), and treatment strategies might differ. Overall, specific recommendations for treatment of nonsevere CM caused by Klebsiella spp. are lacking.

In general, antimicrobial therapy for CM should be as short as possible to reduce use of antimicrobials on farms and to minimize economic losses attributable to discarded milk (Pinzón-Sánchez et al., 2011). As patho- genicity and duration of IMI vary among gram-negative bacteria, different durations of therapy may be recommended to improve clinical and treatment outcomes. The objective of this study was to examine outcomes of 2-d or 8-d IMM treatment using an approved product containing ceftiofur hydrochloride, compared with no treatment of nonsevere, gram-negative cases of CM. Additionally, we contrasted outcomes of CM cases caused by E. coli and Kleb. pneumoniae.

\section{MATERIALS AND METHODS}

\section{Study Design and Herd Characteristics}

A negatively controlled, randomized clinical trial was conducted using dairy cattle from 2 commercial Wisconsin dairy herds that had a single owner. The farms contained approximately 3,656 and 3,386 lactating dairy cows and were located within 6 miles of each other, but cattle did not move between farms. On both farms, cows were housed in freestall barns that contained manure solids as bedding, and cows were milked 3 times a day in rotory parlors by trained milking technicians who used a milking routine that included removal and observation of foremilk.

Both parlors included automated daily milk-yield recording systems, and managers on each farm recorded events in computerized herd records (DairyComp 305, Valley Agricultural Software, Tulare, CA). Cows were enrolled in monthly DHIA testing that included individual cow SCC data, and both sites had trained workers who had a long history of using on-farm culture (OFC) for microbiological diagnosis of CM cases. Gram-negative core antigen vaccines (Bovilis J-5, Merck, Kenilworth, NJ) were routinely given to cows on both farms.

\section{Case Enrollment Criteria}

Eligible cases of CM were enrolled in this study between June and December 2016. Before the study began, researchers trained farm personnel to aseptically collect milk samples and to use a standardized mastitis severity scoring system (Pinzón-Sánchez and Ruegg, 2011). Only nonsevere, gram-negative cases of $\mathrm{CM}$ were eligible for enrollment in this study. Milking technicians identified CM based on observation of foremilk, assigned a severity score, and aseptically collected a milk sample from the affected quarter(s). Nonsevere cases were defined as $\mathrm{CM}$ with mild (abnormal milk) or moderate (abnormal milk accompanied by visible inflammation of the udder) clinical signs. Cows with severe CM (abnormal milk accompanied by systemic 
signs) were not eligible and were treated immediately according to existing farm protocols.

Aseptically collected milk samples were divided into 2 vials. To perform OFC (Lago et al., 2011 a,b), a sterile swab containing approximately $100 \mu \mathrm{L}$ of milk from 1 vial was used to inoculate 3 selective agars: (1) MacConkey agar (selective for gram-negative bacteria), (2) a proprietary medium selective for gram-positive bacteria (MN Biplate, Minnesota Easy Culture System; University of Minnesota Laboratory for Udder Health, St. Paul, MN, 2004), and (3) a proprietary medium selective for streptococci (MN Biplate, Minnesota Easy Culture System; University of Minnesota Laboratory for Udder Health). After inoculation, the remaining milk in the first vial was frozen for further microbiological testing at the University of Wisconsin (UW) Milk Quality laboratory. Milk in the second vial was preserved with bronopol for later SCC analysis. After $24 \mathrm{~h}$ of incubation, trained farm workers observed agar plates for microbial growth. Culture-negative, grampositive, and contaminated cases were not enrolled, and cows were treated according to existing farm protocols. Cases of nonsevere CM caused by gram-negative bacteria were blocked by parity group (primiparous or multiparous) and randomly assigned to an experimental group (described below) by opening envelopes that contained predefined assignments. Researchers assessed compliance with assignments by retrieving envelopes during weekly farm visits.

When CM was detected in $>1$ quarter, all quarters were cultured. If all quarters were gram-negative, all were assigned to the same experimental group. If results of OFC varied among quarters, the cow was not eligible for the study.

After enrollment, if severity failed to improve within $72 \mathrm{~h}$ or when cows developed systemic signs at any time, additional treatment was allowed. Cases that progressed to severe were treated as defined by herd protocols and were removed from the study and categorized as worsened severity for analysis. Voluntary dryoff of quarters of cows affected with $>5$ cases of CM or after $14 \mathrm{~d}$ of continued abnormal milk appearance was a common practice on both herds, and we categorized this practice ("voluntary quarter dry-off") and included it in statistical analyses. After enrollment, when recurrence of $\mathrm{CM}$ occurred in the enrolled quarter or in a different quarter, OFC was again performed, and, contingent on the OFC results, the quarter was assigned to the same experimental group as previously assigned. When OFC results were other than gram-negative, recurrent cases were treated according to farm protocols. All procedures were approved by the Animal Care and Use Committee for the College of Agriculture and Life
Sciences of the University of Wisconsin-Madison (Protocol A01574-0-06-14).

\section{Interventions}

Quarters assigned to receive antimicrobials were given once-daily IMM infusions with a commercially available, approved product containing ceftiofur hydrochloride (Spectramast LC, Zoetis, Parsippany-Troy Hills, NJ) for either $2 \mathrm{~d}$ or $8 \mathrm{~d}$ (per label treatment). Quarters assigned to the negative control group did not receive any antimicrobial therapy. To accommodate existing herd protocols, for moderate cases of CM enrolled in the study, intravenous fluids were administered at enrollment of the case to 23 of 33 cases $(9,8$, and 6 cases assigned to negative control group, $2-\mathrm{d}$, or $8-\mathrm{d}$ treatments, respectively). Milk from all enrolled cows was discarded until it returned to normal (nontreated group) or until the end of the 3-d milk-withholding period after the end of antimicrobial therapy.

\section{Data Collection}

Data collection occurred for $90 \mathrm{~d}$ after enrollment or until the end of lactation (follow-up period, FUP). For the first $10 \mathrm{~d}$ after enrollment, during the midday milking, trained farm workers recorded appearance of the milk and udder, and noted each cow's attitude. During the FUP, farm workers aseptically collected milk samples from recurrent cases of CM and performed OFC. Researchers (farm A) or trained farm workers (farm B) visited farms weekly to aseptically collect milk samples from enrolled quarters at 7 (only one milk sample was collected for SCC analysis), 14, 21, and $28 \pm 3$ d after enrollment, retrieved computerized health records, and assessed study compliance. One milk sample was used for further microbiological analysis, and the other samples were preserved with bronopol and transported to a commercial DHIA laboratory (AgSource CRI, Verona, WI) for SCC analysis.

\section{Microbiological Analysis}

Microbiological analysis of quarter-milk samples collected at $0,14,21$, and $28 \pm 3 \mathrm{~d}$ after enrollment was performed following National Mastitis Council guidelines (NMC, 1999, 2017). Microbiological analysis and definition of IMM infection have been described previously (Fuenzalida et al., 2015; Fuenzalida and Ruegg, 2019). For bacteria identified as gram negative, species were determined using API tests (API 20E, bioMerieux-Vitek Inc., Hazelwood, MO). Quarter milk samples were pooled, and $100 \mu \mathrm{L}$ of the pool was 
inoculated in mycoplasma media broth, and $72 \mathrm{~h}$ later $10 \mu \mathrm{L}$ of this suspension was plated onto one quarter of a mycoplasma agar plate (Media Laboratory, School of Veterinary Medicine at the University of California, Davis, CA). Broth and agar were incubated in $6 \% \mathrm{CO}_{2}$ at $37^{\circ} \mathrm{C}$ for 3 and $14 \mathrm{~d}$, respectively. Mycoplasma agar plates were observed for growth every $2 \mathrm{~d}$ after inoculation until $21 \mathrm{~d}$.

\section{Antimicrobial Susceptibility}

Escherichia coli and Kleb. pneumoniae isolates were sent to the Wisconsin Veterinary Diagnostic Laboratory to conduct in vitro antimicrobial susceptibility tests according to the Clinical and Laboratory Standards Institute (CLSI, 2013). No MIC breakpoints for Kleb. pneumoniae are described in CLSI documents (CLSI, 2015; VET01S) so breakpoints for E. coli were used. Isolates were considered resistant to ceftiofur when the MIC exceeded $4.0 \mu \mathrm{g} / \mathrm{mL}$.

\section{Definitions and Outcomes}

Clinical mastitis was defined when nonsevere signs of inflammation were detected at least $14 \mathrm{~d}$ after a previous case. Subclinical mastitis (SCM) was defined when monthly DHIA SCC was greater than 150,000 cells $/ \mathrm{mL}$ (Lavon et al., 2011). Clinical mastitis history was the occurrence of $\mathrm{CM}$ in the cow (any quarter) within the preceding $55 \mathrm{~d}$ before detection of the enrolled case.

Bacteriological cure at 14 and $21 \mathrm{~d}$ after enrollment was defined as no isolation of bacteria from quarter milk samples collected at both periods. If any bacteria were isolated at 14 or $21 \mathrm{~d}$ after enrollment, then the case was considered bacteriological failure (regardless of pathogen). Regardless of mastitis-causing pathogen, quarter-level CM recurrence (QREC) during the FUP was defined as detection of abnormal milk in the same quarter at least $14 \mathrm{~d}$ after enrollment. Recurrence was evaluated only for cases that achieved clinical cure. Clinical cure was defined as milk returning to normal appearance for at least 2 consecutive days (observations during second milking shift per day) within $10 \mathrm{~d}$ after enrollment. Culling within $21 \mathrm{~d}$ after enrollment was defined as removal of a cow within that period. Voluntary dry-off of an affected quarter was defined as termination of milk production of an enrolled quarter. Days until clinical cure was evaluated for $10 \mathrm{~d}$ after enrollment and was defined as the number of days until milk appeared visually normal. Days of milk discard was the number of days milk was not eligible for sale due to abnormal appearance, treatment, or the withholding period. Days to BC was the time until no bacteria were isolated after enrollment. Days to culling was the number of days until a cow was removed from the herd during FUP. Voluntary quarter dry-off was defined as the time until milking was terminated for an enrolled quarter during the FUP. Daily milk production was automatically collected from milk meters.

\section{Statistical Analysis}

Statistical analyses were conducted using SAS software (version 9.4; SAS Institute, 2011). Quarter was the experimental unit, and analyses followed intentionto-treat principles. The study was designed as a superiority trial, with an overall hypothesis that IMM treatment (for $2 \mathrm{~d}$ or $8 \mathrm{~d}$ ) is superior to no antimicrobial treatment. Binary outcomes were worsened severity, QREC, culling within $21 \mathrm{~d}$, and $\mathrm{BC}$ at 14 and $21 \mathrm{~d}$ after enrollment. Continuous outcomes were daily milk production and weekly quarter-SCC (QSCC) during the FUP. Time-to-event outcomes included days until clinical cure, days of milk discard, days until BC, and days to voluntary quarter dry-off. Categorical explanatory variables were parity group (primiparous, multiparous), severity of CM (mild, moderate), season of enrollment (warm, cool), 3 functional quarters before $\mathrm{CM}$ detection (yes, no), antimicrobial resistance to ceftiofur (yes, no), and SCM or CM history (yes, no). Continuous explanatory variables included SCC between 21 and $55 \mathrm{~d}$ before case detection, average daily milk yield 1 to $7 \mathrm{~d}$ before case detection $(\mathrm{kg} /$ cow per day), and DIM. Somatic cell count data were $\log$-transformed $\left[\log _{10} \mathrm{SCC}=(\mathrm{SCC} \times 1,000\right.$ cells $\left./ \mathrm{mL})\right]$ to follow normal distribution.

Descriptive statistics of farm characteristics, total cases of CM, and cases enrolled in the study were performed using PROC FREQ (SAS Institute, 2011). Chi-squared or Fisher's exact test was used to compare categorical variables, and ANOVA was used to evaluate differences in continuous variables using PROC GLM. Univariate associations between categorical outcomes and selected risk factors were calculated using Chisquared or Fisher's exact test with PROC FREQ. Variables with a $P$-value $<0.25$ were offered for multivariate analysis.

To analyze agreement between microbiological results of UW Milk Quality Laboratory and OFC, the kappa statistic (Cohen, 1960) was calculated using PROC FREQ. Farm personnel categorized bacterial growth on OFC as Klebsiella spp., E. coli, or non-lactose-fermenter. The null hypothesis was that agreement between OFC and UW Milk Quality Laboratory was due to chance. The microbiological categories were Klebsiella spp. and E. coli. 
Number needed to treat (NNT) was calculated to describe the effect of 2-d or 8-d ceftiofur IMM treatment compared with no treatment (Altman and Andersen, 1999).

Survival probabilities were calculated for time-toevent outcomes and selected risk factors using PROC LIFETEST. Time was defined as the number of days until an event of interest occurred. Censoring occurred when the case left the study before the event occurred due to right censoring or lost to follow-up. Survival curves were calculated using the Kaplan-Meier method. Tests of equality over strata were log-rank and Wilcoxon. Log-rank was used to test that probability of occurrence of an event was the same in all groups in all time points. Wilcoxon was used to test that the occurrence of events was the same in all groups early during the FUP. PROC PHREG was used to estimate the hazard ratio at which time-to-event outcomes occurred during the FUP, adjusting for covariates. The proportional hazards assumption was evaluated using the ASSESS statement.

Multivariate logistic regression models were conducted using PROC GLIMMIX. Selected risk factors were offered to the model. Treatment was forced in all models. The effect of fluid therapy for moderate cases was initially assessed in each model, but no effect was found for any outcome, so the variable was dropped from further analysis. Goodness of fit was assessed using -2 Log-likelihood, Akaike's information criterion (AIC), corrected AIC (AICC), and Bayesian information criterion (BIC) of PROC GLIMMIX. Subclinical mastitis was offered as a categorical or continuous variable based on goodness of fit. Each variable offered to the model was evaluated by manual bidirectional elimination until all explanatory variables had $P$-value $<0.10$; subsequently a model was chosen based on parsimony and goodness of fit. Adjusted probabilities of clinical and treatment outcomes were generated using LSMEANS and ODDS RATIO option via PROC GLIMMIX. Cases were not included in an analysis if they had missing data for any variable included in the model.

Model 1 used data from 114 cases to assess the effect of 2-d or 8-d IMM therapy of nonsevere, gram-negative $\mathrm{CM}$ on BC. The alternative hypothesis was that 2-d or 8-d IMM treatment improved the probability of BC, compared to nontreated cases. Bacteriological cure was not assessed in 56 cases due to missing samples $(\mathrm{n}=19)$ or contaminated samples $(\mathrm{n}=37)$ at 14 or $21 \mathrm{~d}$ after enrollment. After model fitting, remaining explanatory variables included experimental groups (forced) and parity group. Additionally, we assessed effects of IMM treatment and type of gram-negative bacteria causing
$\mathrm{CM}$ on BC. Cases of CM that failed to cure $(\mathrm{n}=33)$ and did not have a monthly DHIA $\log _{10}$ SCC 21 to $55 \mathrm{~d}$ before case detection were not included in this analysis $(\mathrm{n}=27)$.

After model fitting, remaining explanatory variables included experimental pathogen group and parity. Model 2 used data from 108 cases to assess the effects of 2-d or 8-d IMM treatment of gram-negative CM on QREC. The alternative hypothesis was that 2-d or 8-d IMM treatment reduced the probability of QREC, compared with nontreated cases. After model fitting, remaining explanatory variables included experimental group (forced), parity group, and $\log _{10} \mathrm{SCC} 21$ to $55 \mathrm{~d}$ before case detection.

Repeated-measures ANOVA was used to analyze daily milk production and QSCC with an autoregressive and unstructured covariance structure, respectively. For daily milk yield, final explanatory variables included experimental group, time, parity group, DIM, voluntary quarter dry-off, average daily milk production 1 to $7 \mathrm{~d}$ before case detection, and 2-way interaction between experimental group and time. The alternative hypothesis was that 2-d or 8-d IMM treatment improved daily milk production over that of nontreated cases. For weekly QSCC final explanatory variables included experimental group, time, severity of CM case enrolled, previous SCM, and bacteriological cure at 14 and $21 \mathrm{~d}$ after case detection. Goodness of fit was assessed using -2 Log-likelihood, AIC, AICC, and BIC of PROC MIXED. Adjusted means of daily milk yield and weekly QSCC were generated using LSMEANS option via PROC MIXED.

\section{RESULTS}

\section{Characteristics of Herds and Cases of Clinical Mastitis}

Parity group distribution varied by farm $(P<0.001)$, and farm $\mathrm{B}$ was composed of slightly younger cows. Cows on farm B had slightly greater $\log _{10} \mathrm{SCC}$ and a greater incidence of $\mathrm{CM}$, and lower average milk production compared with cows on farm A (Table 1).

Characteristics of all cases of CM occurring on the farms during the enrollment period varied by farm $(P$ $<0.05)$. Overall, the distribution of severity of $\mathrm{CM}$ was approximately $75 \%$ mild, $20 \%$ moderate, and $<5 \%$ severe. More than $90 \%$ of cases occurred in a single quarter, and this proportion was slightly greater in farm B compared with farm A.

Of enrolled cases, the distribution of mild and moderate cases varied by farm $(P<0.001)$. The proportion of mild cases were 98 and $40 \%$ for cases enrolled from 
Table 1. Characteristics of commercial dairy farms in Wisconsin used for enrollment of cases of nonsevere clinical mastitis (CM) caused by gram-negative bacteria

\begin{tabular}{|c|c|c|c|c|c|c|c|}
\hline \multirow[b]{2}{*}{ Variable } & \multicolumn{2}{|c|}{ Farm A } & \multicolumn{2}{|c|}{ Farm B } & \multirow[b]{2}{*}{$P$-value } & \multicolumn{2}{|c|}{ All farms } \\
\hline & $\%$ & no. & $\%$ & no. & & $\%$ & no. \\
\hline Parity group & & & & & $<0.001$ & & \\
\hline 1 & 44.7 & 1,634 & 50.4 & 1,707 & & 47.4 & 3,341 \\
\hline 2 & 29.4 & 1,076 & 29.5 & 999 & & 29.5 & 2,075 \\
\hline$\geq 3$ & 25.9 & 946 & 20.1 & 680 & & 23.1 & 1,626 \\
\hline Monthly DHIA milk yield ${ }^{2}(\mathrm{~kg} /$ cow; mean $\pm \mathrm{SEM})$ & & $37.6 \pm 0.1$ & & $35.0 \pm 0.1$ & $<0.001$ & & \\
\hline Incidence of $\mathrm{CM}^{3}($ mean \pm SEM $)$ & & $3.7 \pm 0.3$ & & $4.7 \pm 0.3$ & 0.051 & & \\
\hline Total cases of $\mathrm{CM}^{4}$ (no.) & & 1,848 & & 2,606 & & & 4,454 \\
\hline Severity of $\mathrm{CM}^{5}$ & & & & & 0.027 & & \\
\hline Mild & 71.2 & 1,315 & 74.7 & 1,946 & & 73.2 & 3,261 \\
\hline Moderate & 24.7 & 457 & 21.4 & 557 & & 22.8 & 1,014 \\
\hline Severe & 4.1 & 76 & 3.9 & 103 & & 4.0 & 179 \\
\hline Moderate & 2.2 & 2 & 40.8 & 31 & & 19.6 & 33 \\
\hline
\end{tabular}

${ }^{1}$ Comparisons between farm and parity group or severity of CM or number of quarters affected were performed using Chi-squared analysis or Fisher's exact test. Data used for comparison in this table were obtained during the enrollment period from June through December 2016.

${ }^{2}$ Herd average by farm was calculated from monthly DHIA test data (individual milk yield and SCC).

${ }^{3}$ Number of CM cases per 100 cows per month. The incidence of CM is the number of new cases of CM divided by the number of lactating cows at risk (lactating cows that have not been diagnosed with CM) per month for each year. Cases of CM that occurred $\geq 14 \mathrm{~d}$ from previous cases were considered new cases.

${ }^{4}$ Total cases of CM were counted between July and December 2016.

${ }^{5}$ Mild or moderate cases of CM were considered nonsevere. Severe CM was defined as abnormal milk accompanied by systemic signs.

${ }^{6}$ Number of quarters affected with CM were either single (only 1 quarter was affected with CM) or multiple (more than 1 quarter was affected with CM).

${ }^{7}$ Cows were enrolled from June through December 2016.

farms $\mathrm{A}$ and $\mathrm{B}$, respectively. Fifty-five percent of the cases were enrolled from farm A, and $45 \%$ of the cases were enrolled from farm B. Mycoplasma spp. were not isolated from any milk sample, and all Klebsiella isolates were identified as Kleb. pneumoniae.

\section{Agreement Between OFC and UW Milk Quality Laboratory Results}

Five milk samples from enrolled cases were not available for microbiological diagnosis at the UW Milk Quality Laboratory. Of cases identified as gram-negative bacteria at the UW Milk Quality Laboratory, 56 cases were diagnosed as E. coli, 54 were diagnosed as Kleb. pneumoniae, and 8 were diagnosed as other gramnegative bacteria (Pseudomonas spp. and Serratia).

Of isolates identified by farm workers (using OFC) as Klebsiella spp. $(\mathrm{n}=105), 54$ were confirmed at the UW Milk Quality Laboratory as Kleb. pneumoniae, 21 were identified as E. coli, and 30 were classified as other outcomes (i.e., no growth, contaminated, or mixed in- fection). Of isolates identified by farm workers using OFC as E. coli $(\mathrm{n}=52), 34$ were confirmed at the UW Milk Quality Laboratory as E. coli, 4 were determined to be Kleb. pneumoniae, and 14 were classified as other outcomes (i.e., no growth, contaminated, Serratia spp.).

Observed agreement in diagnosis of gram-negative pathogens between OFC and UW Milk Quality Laboratory was $56 \%$. Kappa coefficient was negative $(\mathrm{Z}=$ $-6.2, P=0.088)$, indicating that agreement was due to chance (Cohen, 1960).

\section{Description of Experimental Groups}

The distribution of severity of CM, season of enrollment, parity group, and CM history did not vary by experimental group (Table 2). Average daily milk production from 1 to $7 \mathrm{~d}$ before cases detection were 39.9 $\pm 1.4,37.2 \pm 1.4$, and $37.4 \pm 1.4 \mathrm{~kg}$ for cows assigned to the negative control, $2-\mathrm{d}$, and 8 -d groups, respectively $(P=0.308)$. Average $\log _{10} \mathrm{SCC} 21$ to $55 \mathrm{~d}$ before cases detection were $5.1 \pm 0.1,5.2 \pm 0.1$, and $5.3 \pm 0.1$ 
$\log _{10}$ SCC for cows assigned to the negative control, 2-d, and 8 -d groups, respectively $(P=0.485)$. Days in milk at case detection were $107.3 \pm 12.6,97.4 \pm 12.6$, and $112.0 \pm 12.6$ for cows assigned to the negative control, 2 -d, and 8 -d groups, respectively $(P=0.705)$.

\section{Bacteriological Cure at 14 and $21 d$ by Experimental Group}

Overall, $65 \%$ of enrolled cases experienced BC. Of categorical explanatory variables, experimental group, parity group, and $\log _{10} \mathrm{SCC} 21$ to $55 \mathrm{~d}$ before case detection met criteria for entry into multivariate model (Table 3 ). $\log _{10} \mathrm{SCC} 21$ to $55 \mathrm{~d}$ before case detection were $5.1 \pm 0.1$ and $5.5 \pm 0.1 \log _{10} \mathrm{SCC}$ for cows that experienced and did not experienced $\mathrm{BC}$, respectively $(P=0.036)$.

After model building, the final logistic regression model for the effect of experimental group (negative control, 2-d or 8-d IMM ceftiofur) on BC included experimental group and parity group (Table 4). Compared with cows in the negative control group, IMM treatment increased the probability of $\mathrm{BC}(P=0.025)$. Odds of $\mathrm{BC}$ were 4 times greater in quarters treated with 8-d IMM therapy than in quarters that did not receive treatment. Odds of $\mathrm{BC}$ were 2 times greater in quarters treated using 2-d IMM therapy than in quarters in the negative control group. Compared with quarters of primiparous cows, quarters of multiparous cows were approximately 10 times less likely to experience BC $(P=0.011)$.

\section{Bacteriological Cure at 14 and 21 d by Pathogen Combined with Experimental Group}

More than $80 \%$ of quarter milk samples were culture negative at 14, 21, and $28 \pm 3 \mathrm{~d}$ after enrollment (Figure 1). Klebsiella pneumoniae was consistently isolated in quarter milk samples from 14 to $28 \pm 3 \mathrm{~d}$ after enrollment, and E. coli was rarely isolated in quarter milk samples during the same period (Figure 1).

Of enrolled cases of CM, 41 were caused by E. coli and assigned to negative control $(\mathrm{n}=16), 2$-d IMM ceftiofur $(\mathrm{n}=11)$, or 8-d IMM ceftiofur $(\mathrm{n}=14)$, and 36 were caused by Kleb. pneumoniae and assigned to negative control $(\mathrm{n}=11), 2$-d IMM ceftiofur $(\mathrm{n}=14)$, or 8-d IMM ceftiofur $(\mathrm{n}=11)$. Bacteriological cure at 14 and $21 \mathrm{~d}$ after enrollment $(P<0.001)$ and parity group $(P=0.006)$ were associated with experimental group and pathogen. For cases caused by E. coli, proportions of BC were 93.7 (negative control), 100 (2-d IMM ceftiofur), and 92.9\% (8-d IMM ceftiofur). For cases caused by Kleb. pneumoniae, proportions of BC were 9.1 (negative control), 42.9 (2-d IMM ceftiofur), and $63.6 \%$ (8-d IMM ceftiofur). For CM caused by $E$. coli or Kleb. pneumoniae, odds of BC were not associated with duration of IMM treatment $(2 \mathrm{~d}$ or $8 \mathrm{~d})$, so both IMM groups were combined (i.e., treated) for further analysis.

The final logistic model for the effect of experimental group (negative control, 2-d, or 8-d IMM ceftiofur) and pathogen on BC included experimental group, pathogen, and parity (Table 5). For nontreated quarters,

Table 2. Description of clinical mastitis $(\mathrm{CM})$ cases $(\mathrm{n}=168)$ enrolled in the study by experimental group

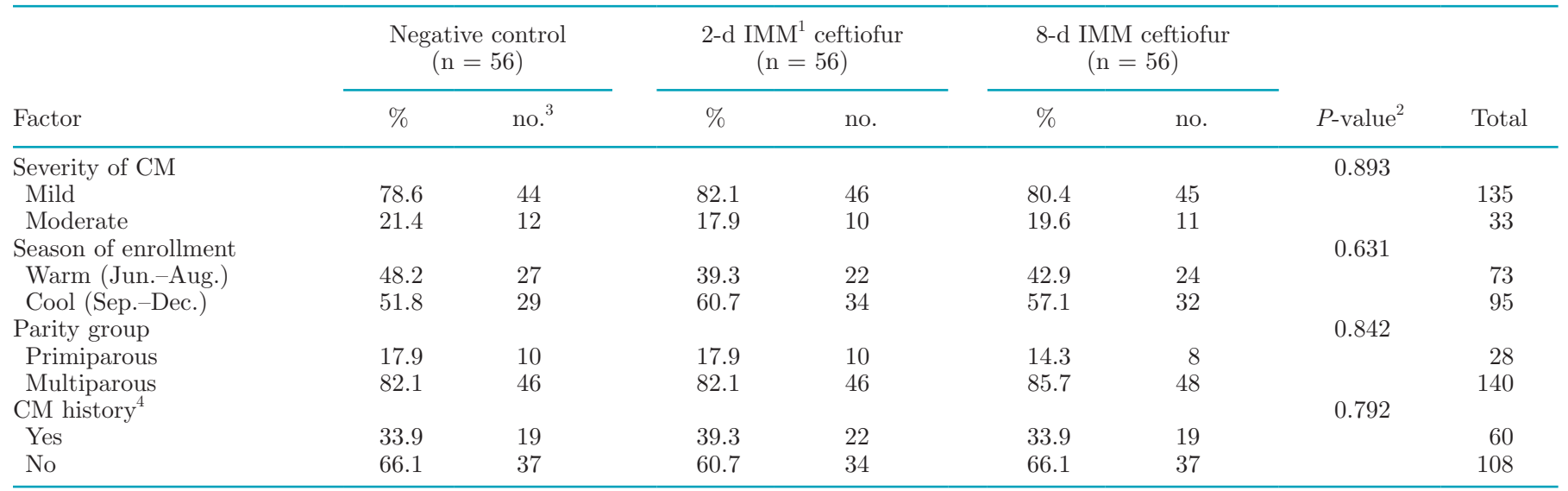

${ }^{1}$ Intramammary.

${ }^{2}$ Comparisons among experimental groups were performed using Chi-squared analysis or Fisher's exact test.

${ }^{3}$ Calculated by dividing the number of observation (n) by the total number of cases per experimental group.

${ }^{4}$ Previous CM history within $55 \mathrm{~d}$ before case detection. 
Table 3. Univariate associations between selected risk factors and quarter-level clinical mastitis (CM) recurrence (QREC), or bacteriological cure (BC) at 14 and $21 \mathrm{~d}$ after enrollment ${ }^{1}$

\begin{tabular}{|c|c|c|c|c|c|c|}
\hline \multirow[b]{2}{*}{ Predictor } & \multicolumn{3}{|c|}{$\mathrm{BC}(\mathrm{n}=114)^{2}$} & \multicolumn{3}{|c|}{$\operatorname{QREC}(\mathrm{n}=135)^{3}$} \\
\hline & $\%$ & no. & $P$-value ${ }^{1}$ & $\%$ & no. & $P$-value \\
\hline Experimental group & & & 0.039 & & & 0.976 \\
\hline Negative control & 51.2 & $21 / 41$ & & 39.5 & $17 / 43$ & \\
\hline 2-d IMM ${ }^{4}$ ceftiofur & 70.3 & $26 / 37$ & & 41.9 & $18 / 43$ & \\
\hline 8-d IMM ceftiofur & 77.8 & $28 / 36$ & & 40.8 & $20 / 49$ & \\
\hline Severity of CM & & & 0.932 & & & 0.792 \\
\hline Mild & 65.6 & $63 / 96$ & & 41.3 & $45 / 109$ & \\
\hline Moderate & 66.7 & $12 / 18$ & & 38.5 & $10 / 26$ & \\
\hline Season of enrollment & & & 0.554 & & & 0.106 \\
\hline Warm (Jun.-Aug.) & 63.2 & $36 / 57$ & & 49.1 & $27 / 55$ & \\
\hline Cool (Sep.-Dec.) & 68.4 & $39 / 57$ & & 35.0 & $28 / 80$ & \\
\hline Parity group & & & 0.008 & & & 0.005 \\
\hline Primiparous & 90.5 & $19 / 21$ & & 16.0 & $4 / 25$ & \\
\hline Multiparous & 60.2 & $56 / 93$ & & 46.4 & $51 / 110$ & \\
\hline CM history ${ }^{5}$ & & & 0.323 & & & 0.351 \\
\hline Yes & 59.5 & $22 / 37$ & & 46.5 & $20 / 43$ & \\
\hline No & 68.8 & $53 / 77$ & & 38.0 & $35 / 92$ & \\
\hline
\end{tabular}

${ }^{1}$ Comparisons between outcomes and risk factors were performed using Chi-squared analysis or Fisher's exact test.

${ }^{2}$ Bacteriological cure at 14 and $21 \mathrm{~d}$ after enrollment was defined as no isolation of bacteria from follow-up quarter milk samples at either period. Bacteriological cure was not assessed in 56 cases due to missing samples $(\mathrm{n}=19)$ or contaminated samples $(\mathrm{n}=37)$ at 14 or $21 \mathrm{~d}$ after enrollment.

${ }^{3}$ Quarter-level CM recurrence was the detection of new CM event at least $14 \mathrm{~d}$ after enrollment during a 90-d follow-up period or until dry-off. Cases of CM that failed to cure $(\mathrm{n}=33)$ were not included in the analysis.

${ }^{4}$ Intramammary.

${ }^{5}$ Previous CM history within 55 d before case detection.

Table 4. Final logistic regression models for the effect of experimental group assigned to nonsevere, gram-negative clinical mastitis (CM) on bacteriological cure (BC) at 14 and $21 \mathrm{~d}$ after enrollment, and quarter-level CM recurrence

\begin{tabular}{|c|c|c|c|c|c|}
\hline Predictor & no. & $\mathrm{LSM}^{1}$ & SEM & $\begin{array}{c}\text { Odds ratio } \\
(95 \% \text { CI })\end{array}$ & $P$-value \\
\hline \multicolumn{6}{|l|}{ Bacteriological cure $(\mathrm{n}=114)^{2}$} \\
\hline Intercept & & 1.705 & 0.769 & & \\
\hline Negative control & 41 & 0.667 & 0.099 & Referent & \\
\hline 2-d IMM ${ }^{3}$ ceftiofur & 37 & 0.843 & 0.068 & $2.67(0.99,7.24)$ & 0.053 \\
\hline 8-d IMM ceftiofur & 36 & 0.889 & 0.054 & $4.01(1.39,11.52)$ & 0.010 \\
\hline \multicolumn{6}{|l|}{ Quarter-level recurrence $(\mathrm{n}=108)^{4}$} \\
\hline Intercept & & -4.192 & 1.343 & & \\
\hline Experimental group & & & & & 0.990 \\
\hline Negative control & 37 & 0.323 & 0.093 & & \\
\hline 2-d IMM ceftiofur & 33 & 0.337 & 0.097 & & \\
\hline 8-d IMM ceftiofur & 38 & 0.322 & 0.088 & & \\
\hline
\end{tabular}

${ }^{1}$ Estimates of predicted probabilities of treatment outcomes were described on the scale of the mean (inverse linked scale).

${ }^{2}$ Bacteriological cure was not assessed in 56 cases due to missing samples $(\mathrm{n}=19)$, or contaminated samples $(\mathrm{n}=37)$ at 14 or $21 \mathrm{~d}$ after enrollment.

${ }^{3}$ Intramammary.

${ }^{4}$ Cases of CM that failed to be cured $(\mathrm{n}=33)$ and did not have a monthly $\log _{10} \mathrm{SCC} 21$ to $55 \mathrm{~d}$ before case detection were not included in this analysis $(\mathrm{n}=27)$.

${ }^{5} \log _{10} \mathrm{SCC} 21$ to 55 d before case detection. 
Table 5. Final logistic regression model for the effect of intramammary treatment and type of gram-negative bacteria (Escherichia coli and Klebsiella pneumoniae) causing nonsevere clinical mastitis $(\mathrm{CM})$ on bacteriological cure (BC; $\mathrm{n}=77)$

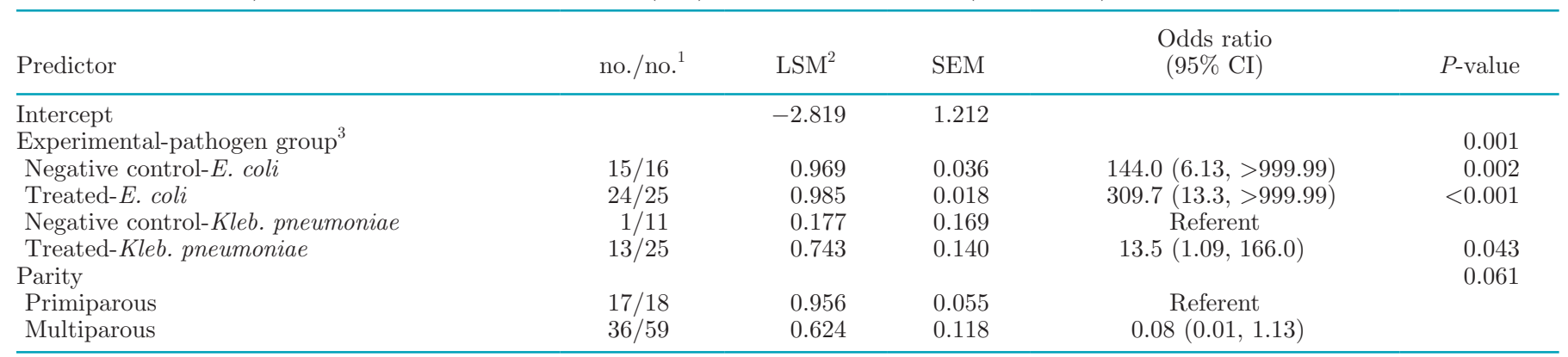

${ }^{1}$ Raw proportion of BC by treatment-pathogen group and parity group. Bacteriological cure was not assessed in 15 (E. coli) and 18 (Kleb. pneumoniae) cases; these cases were not included in the analysis due to missing or contaminated samples.

${ }^{2}$ Estimates of predicted probabilities of $\mathrm{BC}$ were described on the scale of the mean (inverse linked scale).

${ }^{3}$ The 2-d and 8-d intramammary ceftiofur groups were combined into one category, defined as "treated."

BC was approximately 144 times more likely $(95 \%$ CI: $6.13,>999.99)$ for cases caused by $E$. coli than for cases caused by Kleb. pneumoniae. Compared to treated quarters with CM caused by Kleb. pneumoniae, BC was approximately 11 times more likely (95\% CI: 1.11, 103.14) for nontreated quarters caused by E. coli. For quarters affected with Kleb. pneumoniae, the odds of BC were 13.4 times (95\% CI: 1.09, 166.1) greater for treated cases than for nontreated control quarters $(P=$ 0.043). For quarters affected with $E$. coli, the odds of
$\mathrm{BC}$ were not associated with experimental group (Table 5). Compared with multiparous cows, primiparous cows were approximately 13 times more likely to experience BC (95\% CI: 0.88, 190.92).

\section{Bacteriological Cure at 14 and 21 d by In Vitro Ceftiofur Susceptibility}

Of $56 \mathrm{E}$. coli isolates, only one isolate was considered resistant to ceftiofur ( $\mathrm{MIC} \geq 4.0 \mu \mathrm{g} / \mathrm{mL}$ ). Of 54
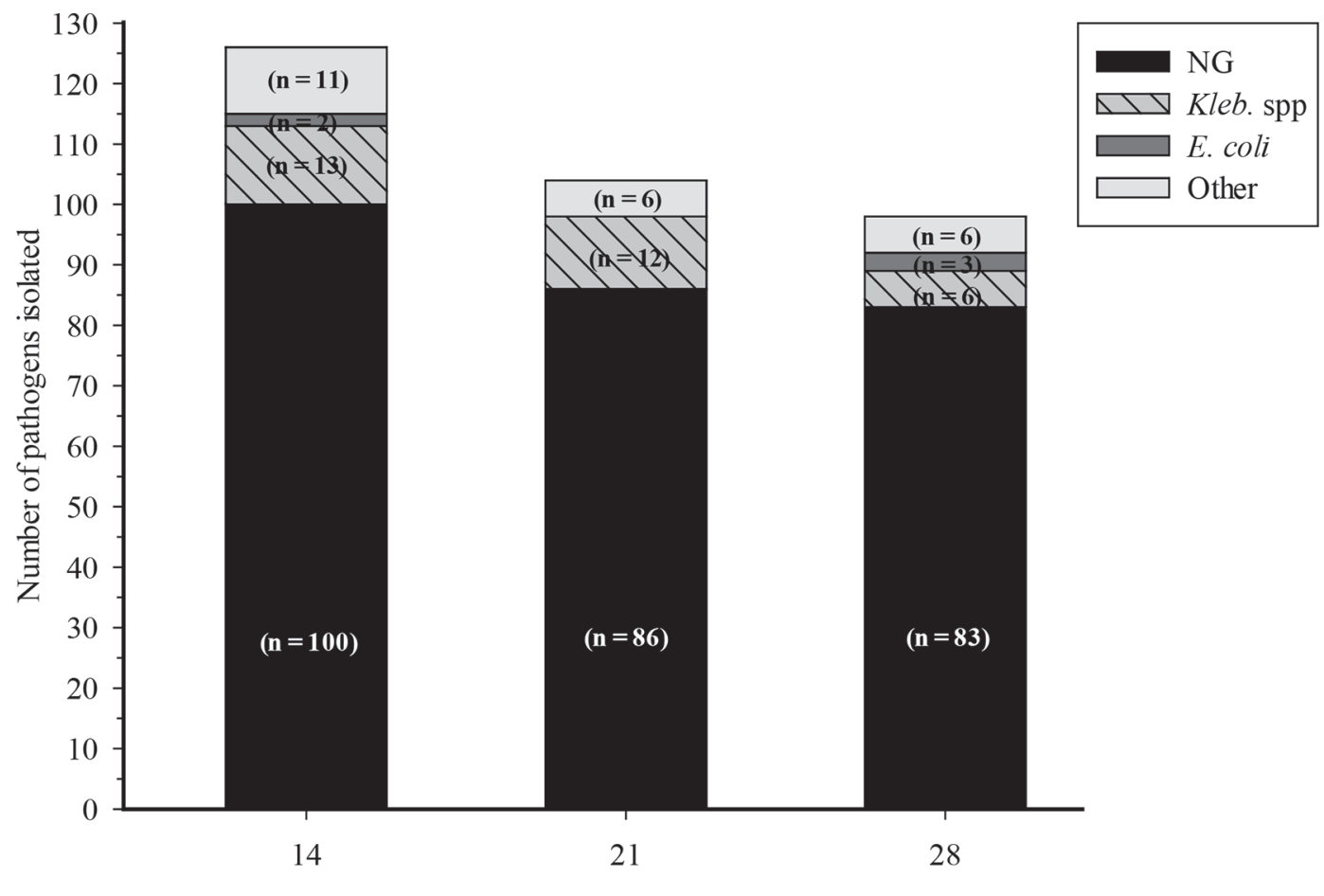

Days after enrollment

Figure 1. Number of pathogens isolated during the follow-up period. Culture negative (NG), Klebsiella spp. (Kleb. spp.), Escherichia coli, and other (Serratia spp., mixed infection, Citrobacter spp., Corynebacterium spp., NAS, environmental streptococci). 
Kleb. pneumoniae isolates, the MIC of $32 \%$ of Kleb. pneumoniae exceeded $\geq 4.0 \mu \mathrm{g} / \mathrm{mL}$ and, based on CLSI breakpoint for $E$. coli, would have been considered resistant. Cases caused by Kleb. pneumoniae that were considered resistant $(\mathrm{n}=25)$ had a lower probability of $\mathrm{BC}$ at 14 and $21 \mathrm{~d}$ after enrollment $(7.7 \%, \mathrm{n}=1)$ than did cases caused by isolates that were considered susceptible $(92.3 \%, \mathrm{n}=12 ; P=0.048)$.

\section{Quarter-Level Recurrence}

Of enrolled cases, $41 \%$ developed QREC within the FUP (Table 3). Of explanatory variables, season of enrollment, parity group, $\log _{10} \mathrm{SCC} 21$ to $55 \mathrm{~d}$ before case detection, and average daily milk yield 1 to $7 \mathrm{~d}$ before case detection met criteria for entry into the multivariate model. $\log _{10} \mathrm{SCC} 21$ to $55 \mathrm{~d}$ before case detection were $5.4 \pm 0.1$ for cows that experienced QREC, in contrast to $4.9 \pm 0.1$ for cows that did not experience QREC $(P=0.004)$. Average daily milk production 1 to $7 \mathrm{~d}$ before case detection were $39.7 \pm 1.4 \mathrm{~kg}$ and $37.1 \pm$ $1.2 \mathrm{~kg}$ for cows experiencing QREC in contrast to cows that did not experience QREC $(P=0.170)$.

After model building, the final logistic regression model for the effect of experimental group (negative control, 2-d or 8-d IMM ceftiofur) on QREC included experimental group (forced), parity group, and $\log _{10} \mathrm{SCC}$ 21 to $55 \mathrm{~d}$ before case detection. Experimental group was not associated with probability of QREC $(P=$ 0.990). Odds of QREC were almost 3 times greater for multiparous cows than for primiparous cows. For every 1-unit increase in $\log _{10} \mathrm{SCC} 21$ to $55 \mathrm{~d}$ before case detection, the probability of QREC increased by $57 \%(P=$ 0.026; Table 4).

The power to detect differences in the probability of QREC by experimental group was 0.06. If the true probability of QREC were $39.5 \%$ (negative control), $41.9 \%$ (2-d IMM ceftiofur), and 40.8\% (8-d IMM ceftiofur; Table 3), 22,477 cases would be needed in each experimental group to reject the null hypothesis $(P=$ $0.80)$.

\section{Worsened Severity and Culling Within $21 d$ After Enrollment}

Of enrolled cases, $8 \%$ experienced worsened severity after enrollment. Of cases that experienced worsened severity after enrollment, $7 \%(\mathrm{n}=4), 5 \%(\mathrm{n}=3)$, and $11 \%(\mathrm{n}=6)$ were observed in negative control, 2 - $\mathrm{d}$ and 8-d groups, respectively. Experimental group was not associated with worsened severity $(P=0.674)$.

Of enrolled cases, $6 \%$ were culled within $21 \mathrm{~d}$ after enrollment. Of cows that were culled within $21 \mathrm{~d}$ after enrollment, $9 \%(\mathrm{n}=5), 4 \%(\mathrm{n}=2)$, and $5 \%(\mathrm{n}=$
3) were removed from the negative control, 2-d, and 8-d groups, respectively. Experimental group was not associated with culling within $21 \mathrm{~d}$ after enrollment $(P$ $=0.609$ ).

\section{Number Needed to Treat}

Based on LSM of BC by experimental group (Table 4), 5 quarters would require 2-d IMM ceftiofur treatment to result in 1 additional BC (95\% CI: 5, 9), and 4 quarters would require 8-d IMM ceftiofur treatment to result in 1 additional BC $(95 \%$ CI: 3,7$)$. Number needed to treat for QREC was not calculated, because the rate of QREC in the negative-control and 8-d IMM ceftiofur treatment were the same, and QREC was greater for 2-d IMM ceftiofur treatment than for cases with no IMM treatment.

\section{Survival Analysis}

Days to Clinical Cure. Mean days to clinical cure was $4.3 \pm 0.2 \mathrm{~d}$. The probability of clinical cure within $10 \mathrm{~d}$ after enrollment was not associated with season of enrollment $(P=0.914)$, parity group $(P=0.476)$, previous $\operatorname{SCM}(P=0.656)$, or experimental group $(P=$ $0.593)$ but was associated with CM history $(P=0.024)$ and severity of $\mathrm{CM}(P=0.015)$. Average duration until clinical cure were $4.2 \pm 0.3,4.8 \pm 0.3$, and $4.5 \pm 0.3 \mathrm{~d}$ for cases in the negative control, 2-d treatment, and 8-d treatment groups, respectively (Figure 2a). Of quarters in the negative control group, $14.3 \%$ were censored, based on no clinical cure $(\mathrm{n}=4)$ or lost to follow-up $(\mathrm{n}=4)$. Of quarters that received 2-d IMM ceftiofur treatment, $12.5 \%$ were censored, based on no clinical cure $(\mathrm{n}=5)$ or lost to follow-up $(\mathrm{n}=2)$. Of quarters that received 8-d IMM ceftiofur treatment, $14.3 \%$ were censored, based on no clinical cure $(\mathrm{n}=1)$ or lost to follow-up $(\mathrm{n}=7)$.

The probability of clinical cure was the same among experimental groups at all time points (Log-rank test, $P=0.593$ ) and early time points (Wilcoxon test, $P=$ 0.511) during $10 \mathrm{~d}$ after enrollment (Figure 2a). By d 5 after enrollment, more than $70 \%$ of the cases in all groups experienced clinical cure among experimental groups. By d 10 after enrollment, 92, 98, and 90\% of the cases experience clinical cure in the negative control, 2-d and 8-d IMM ceftiofur treatment groups, respectively (Figure 2a).

Days Milk Discarded. Milk was discarded for 7.4 $\pm 0.3 \mathrm{~d}$. The probability of milk returning to the tank was not associated with season of enrollment $(P=$ $0.653)$, severity of $\mathrm{CM}(P=0.528)$, parity group $(P=$ $0.999)$, previous SCM $(P=0.719)$, or CM history ( $P$ $=0.150)$ but was associated with experimental group 
a)

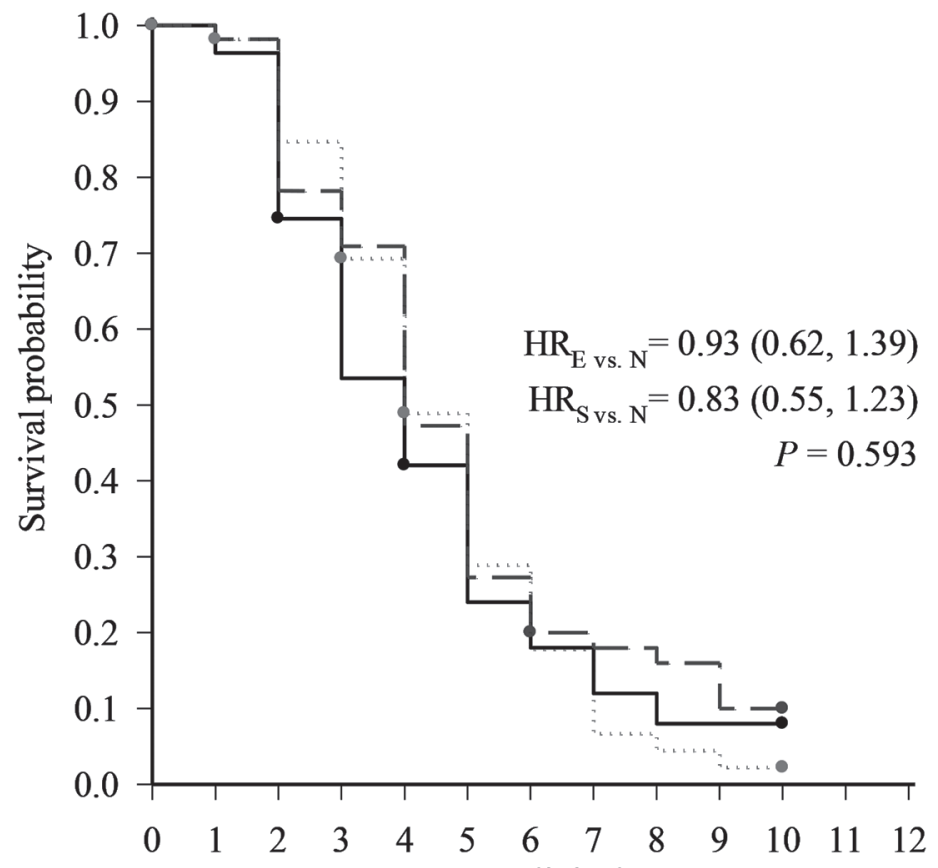

b)

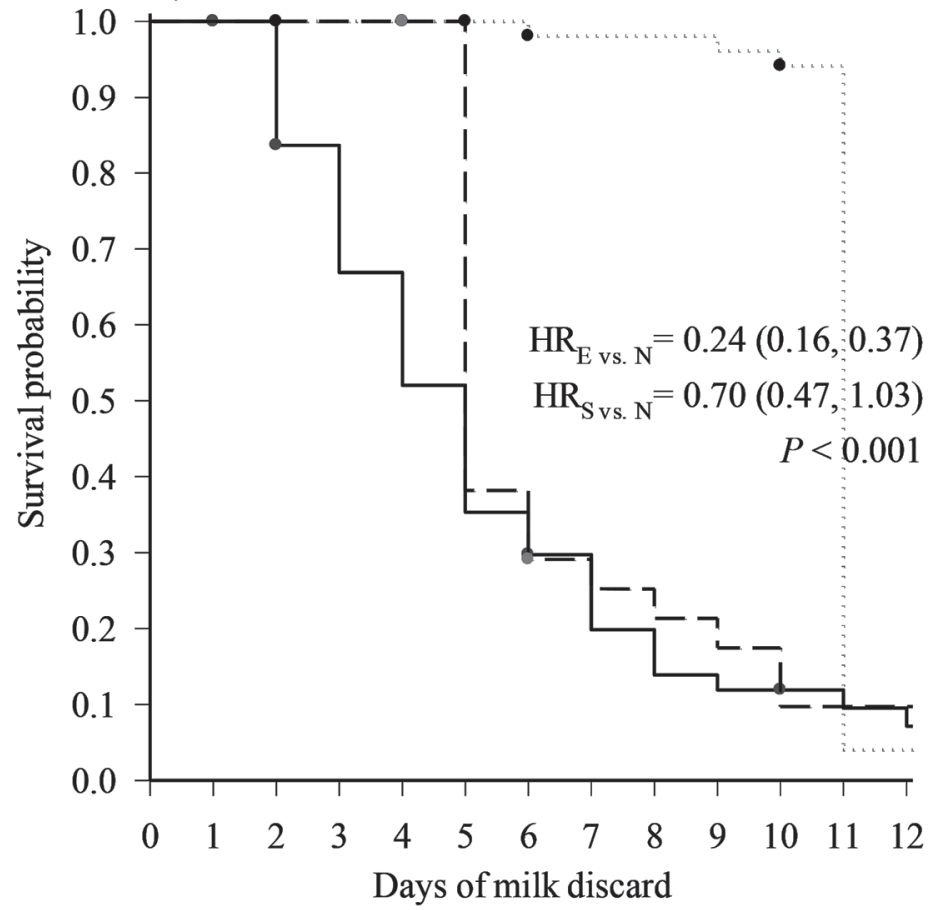

c)

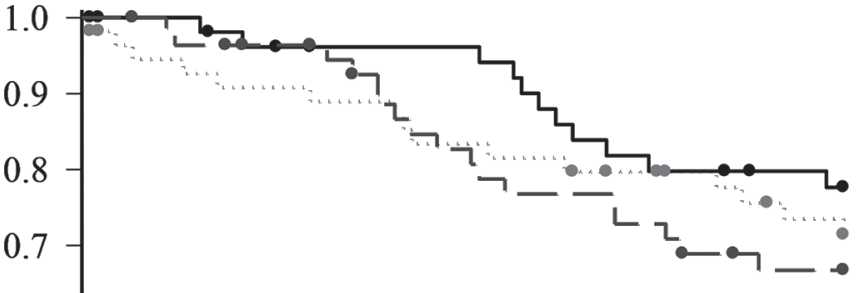

$\mathrm{HR}_{\mathrm{E} \text { vs. } \mathrm{N}}=1.59(0.70,3.58)$

$\mathrm{HR}_{\text {Sv. } \mathrm{N}}=1.98(0.89,4.43)$

$P=0.434$

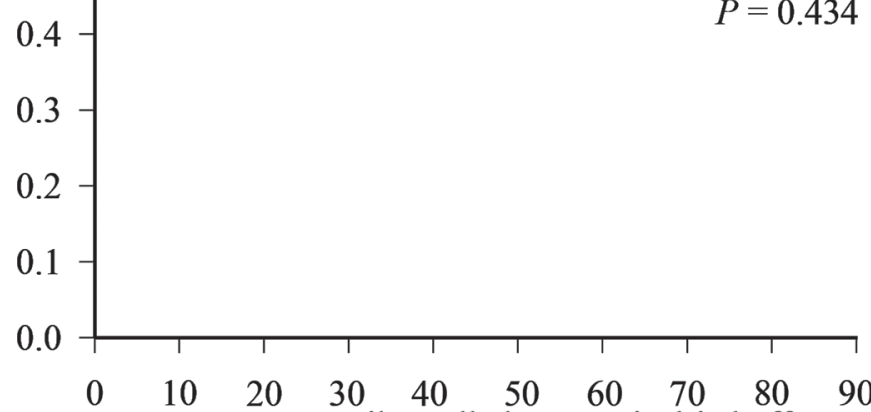

d)

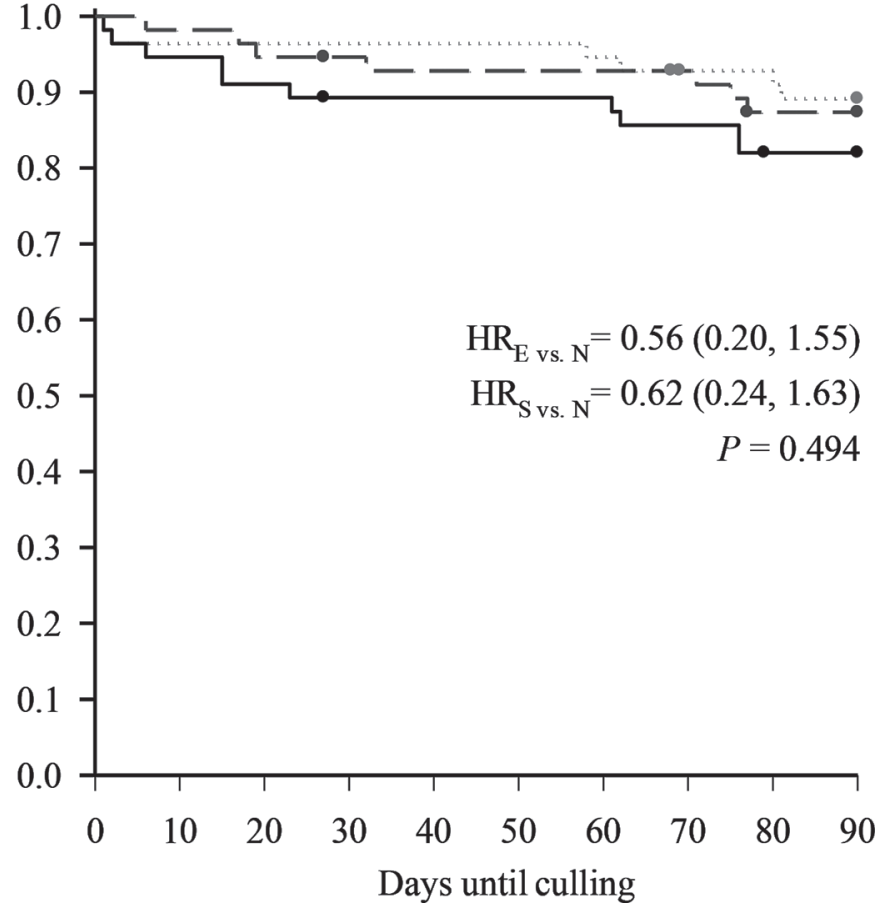

Figure 2. Unadjusted survival plots describing the probability of (a) clinical cure $(\mathrm{n}=168)$, (b) days of milk discard ( $\mathrm{n}=168)$, (c) days to quarter dry-off $(\mathrm{n}=168)$, and $(\mathrm{d})$ culling $(\mathrm{n}=168)$ by experimental group: negative control (solid line, N), 2-d intramammary (IMM) ceftiofur (dashed line, S), and 8-d IMM ceftiofur (dotted line, E). HR = hazard ratio. Values in parentheses represent $95 \%$ CI.

$(P<0.001$; Figure 2b). Average durations of milk discard were $5.6 \pm 0.5,6.9 \pm 0.5$, and $11.1 \pm 0.2 \mathrm{~d}$ for cases in the negative control, 2-d IMM treatment and 8-d IMM treatment, respectively. Of quarters in the negative control group, $7.1 \%$ were censored, based on lost to follow-up $(\mathrm{n}=4)$. Of quarters that received 2-d 
IMM ceftiofur treatment, $5.4 \%$ were censored, based on lost to follow-up $(\mathrm{n}=3)$. Of quarters that received 8-d IMM ceftiofur treatment, $10.7 \%$ were censored, based on case not having the milk returned to the tank $(\mathrm{n}=$ 1) or lost to follow-up $(\mathrm{n}=5)$.

The probability of milk returning to the tank was not the same among experimental groups at all time points (Log-rank test, $P<0.001$ ) or early time points (Wilcoxon test, $P<0.001$ ) within $12 \mathrm{~d}$ after enrollment (Figure 2b). By d 6 after enrollment, milk was returned to the tank in 65,71 , and $2 \%$ of the cases in the negative control, 2-d, and 8-d IMM treatment groups, respectively. By d 11 after enrollment, milk was returned to the tank in 91,92 , and $96 \%$ of the cases in the negative control, 2-d, and 8-d IMM treatment groups, respectively (Figure $2 \mathrm{~b}$ ).

Days to Voluntary Quarter Dry-Off. Fortythree enrolled quarters were dried off during the FUP and were distributed among the negative control group $(\mathrm{n}=11), 2-\mathrm{d}$ IMM treatment group $(\mathrm{n}=17)$, and 8-d IMM treatment group $(\mathrm{n}=15)$. The probability of drying off a quarter was not associated with severity of CM $(P=0.398)$, season of enrollment $(P=0.171)$, or experimental group $(P=0.434)$ but was associated with CM history $(P=0.002)$ and previous SCM $(P$ $<0.001$; Figure 2c). Average duration until enrolled quarters were dried off were $80.4 \pm 2.6,68.7 \pm 2.8$, and $76.3 \pm 3.8 \mathrm{~d}$ for cases in the negative control, 2 -d IMM treatment, and 8-d IMM treatment, respectively.

The probability of drying off a quarter was the same among experimental groups at all time points (Logrank test, $P=0.434$ ) and early time points (Wilcoxon test, $P=0.398$ ) during the FUP (Figure 2c). By d 30 after enrollment, 6, 7, and $13 \%$ of enrolled quarters were dried off from the negative control, 2-d, and 8-d IMM treatment groups, respectively. By d 60 after enrollment, 18, 27, and $22 \%$ of enrolled quarters were dried off from the negative control, 2-d, and 8-d IMM ceftiofur treatment groups, respectively. By d 90 after enrollment, 22, 33, and $29 \%$ of enrolled quarters were dried off from the negative control, 2-d, and 8-d IMM ceftiofur treatment groups, respectively (Figure 2c).

After adjusting for CM history $(P=0.033)$, type of gram-negative pathogen was associated with the probability of voluntary quarter dry-off $(P=0.002)$. During the FUP, 4 times as many quarters were dried off for CM caused by Kleb. pneumoniae $(\mathrm{n}=21 / 54)$ compared with CM caused by E. coli $(\mathrm{n}=6 / 56 ; 95 \%$ CI: 1.68 , 10.73). Average duration until enrolled quarters were dried off were $89.2 \pm 2.1$, and $69.9 \pm 3.7 \mathrm{~d}$ for cases of CM caused by E. coli and Kleb. pneumoniae, respectively. For cases of CM caused by Kleb. pneumoniae (n $=54)$ and after adjusting for CM history $(P=0.040)$, ceftiofur susceptibility was associated with the prob- ability of voluntary quarter dry-off $(P=0.014)$. During FUP, 3 times as many quarters were dried off for CM caused by Kleb. pneumoniae isolates resistant to ceftiofur $(\mathrm{n}=9 / 17)$ compared to susceptible isolates $(\mathrm{n}=$ 12/37; 95\% CI: 1.25, 7.30).

Days to Culling. No deaths were reported during the 90-d FUP. Twenty-three cows were culled during the FUP and were distributed among experimental groups as negative control $(\mathrm{n}=10), 2$-d IMM treatment group $(\mathrm{n}=7)$, and 8-d IMM treatment group (n $=6$; Figure $2 \mathrm{~d}$ ). The probability of remaining in the herd during the FUP was not associated with severity of CM $(P=0.378)$, season of enrollment $(P=0.066)$, CM history $(P=0.077)$, previous $\mathrm{SCM}(P=0.254)$, or experimental group $(P=0.494$; Figure $2 \mathrm{~d})$. Average duration until cows were culled were $68.4 \pm 2.9$, $72.7 \pm 2.2$, and $77.4 \pm 2.2 \mathrm{~d}$ for cases in the negative control, 2-d IMM treatment, and 8-d IMM treatment, respectively.

The probability of remaining in the herd was the same among experimental groups at all time points (Log-rank test, $P=0.494$ ) and early time points (Wilcoxon test, $P=0.460$ ) during the FUP (Figure $2 \mathrm{~d}$ ). By d 60 after enrollment, $87 \%$ (negative control), $91 \%$ (2-d IMM ceftiofur), and 93\% (8-d IMM ceftiofur) of cows remained in the herd. By d 90 after enrollment, $82 \%$ (negative control), $87 \%$ (2-d IMM ceftiofur), and $89 \%$ (8-d IMM ceftiofur) of cows remained in the herd (Figure 2d). Post-hoc power analysis indicated that to find differences in survival probabilities among negative control group and 2-d or 8-d IMM treatment, we would have needed to enroll at least 5,406 cases per experimental group.

Type of gram-negative bacteria causing CM was associated with the probability of culling $(P=0.040)$. During the FUP, 3 times as many cows were culled for cases caused by Kleb. pneumoniae $(\mathrm{n}=12 / 54)$ than for cases caused by $E$. coli $(\mathrm{n}=4 / 56 ; 95 \%$ CI: 1.05 , 10.09). For cases of CM caused by Kleb. pneumoniae (n $=41$ ) and after adjusting for previous SCM history $(P$ $=0.029)$, ceftiofur susceptibility was associated with the probability of culling $(P=0.018)$. During the FUP, 5 times as many cows were culled for CM caused by Kleb. pneumoniae isolates resistant to ceftiofur $(\mathrm{n}=$ $5 / 12)$ compared to isolates susceptible ( $\mathrm{n}=5 / 29 ; 95 \%$ CI: 1.31, 19.40).

Days to Bacteriological Cure. The probability of $\mathrm{BC}$ during the FUP was not associated with severity of CM $(P=0.629)$, season of enrollment $(P=0.967)$, or CM history $(P=0.084)$, but was associated with parity group $(P=0.028)$, previous SCM $(P=0.013)$, and experimental group $(P=0.022$; Figure 3$)$. Average duration until $\mathrm{BC}$ were $18.1 \pm 0.9,17.2 \pm 0.9$, and $15.3 \pm 0.7 \mathrm{~d}$ for cases in the negative control, $2-\mathrm{d}$ 


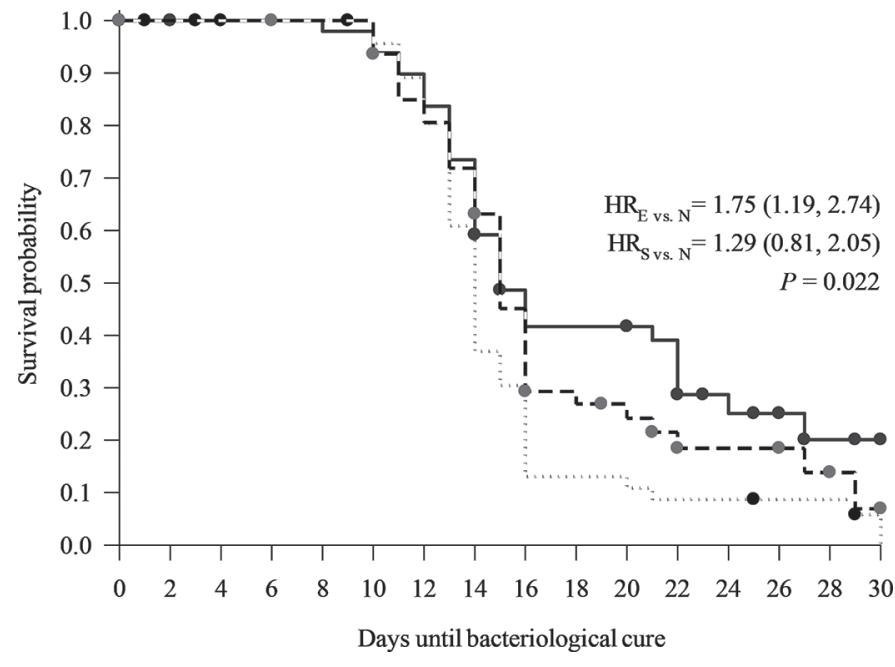

Figure 3. Unadjusted survival plot describing the probability of bacteriological cure $(\mathrm{n}=155)$ by experimental group: negative control (solid line, N), 2-d intramammary (IMM) ceftiofur (dashed line, S), and 8-d IMM ceftiofur (dotted line, E). HR = hazard ratio. Values in parentheses represent $95 \%$ CI.

IMM treatment group and 8-d IMM treatment group, respectively. Of quarters in the negative control group, $32.7 \%$ were censored, based on cases not experiencing $\mathrm{BC}(\mathrm{n}=12)$ or lost to follow-up $(\mathrm{n}=5)$. Of quarters that received 2-d IMM treatment, $22.5 \%$ were censored, based on cases not experiencing $\mathrm{BC}(\mathrm{n}=6)$ or lost to follow-up $(\mathrm{n}=5)$. Of quarters that received 8-d IMM treatment, $18.5 \%$ were censored, based on cases not experiencing $\mathrm{BC}(\mathrm{n}=2)$ or lost to follow-up $(\mathrm{n}=8)$. After accounting for parity group $(P=0.050) \mathrm{BC}$ during FUP was associated with experimental group $(P=$ 0.048).

The probability of $\mathrm{BC}$ was not the same among experimental groups at all time points (Log-rank test, $P$ $=0.022$ ), but the probability was the same during early time points (Wilcoxon test, $P=0.063$ ) after enrollment (Figure 3). By d 14 after enrollment, 41, 37, and 39\% of the cases experienced $\mathrm{BC}$ in the negative control, 2-d, and 8-d IMM treatment groups, respectively. By d 21 after enrollment, 61, 78, and $91 \%$ of the cases experienced $\mathrm{BC}$ in the negative control, 2- $\mathrm{d}$, and $8-\mathrm{d}$ IMM treatment groups, respectively. By d 28 after enrollment, 80, 93, and $94 \%$ of the cases experienced BC in the negative control, 2-d, and 8-d IMM treatment groups (Figure 3 ).

For CM caused by E.coli or Kleb. pneumoniae, hazard ratio of $\mathrm{BC}$ was not different between cases treated with 8-d versus 2-d IMM ceftiofur (95\% CI: 0.94, 2.72), so both groups were combined. After accounting for parity group $(P=0.063)$ type of gram-negative bacteria causing $\mathrm{CM}$ combined with experimental group (treated versus not treated with IMM ceftiofur) was associated with probability of $\mathrm{BC}(P<0.001)$. For nontreated quarters, 6 times as many quarters experienced $\mathrm{BC}$ during the FUP after CM caused by E. coli, compared with cases caused by Kleb. pneumoniae (95\% CI: 2.31, 16.58). During the FUP, twice as many cases experienced BC for cases caused by Kleb. pneumoniae and treated with IMM ceftiofur, compared with cases caused by Kleb. pneumoniae and not treated with IMM ceftiofur (95\% CI: 1.02, 6.28). Twice as many cases experienced BC for cases caused by E. coli and not treated with IMM ceftiofur, compared with cases caused by Kleb. pneumoniae and treated with IMM ceftiofur (1.23, 4.84). For primiparous cows, twice many quarters experienced $\mathrm{BC}$ during the FUP compared with multiparous cows enrolled in the study (95\% CI: 0.97, 2.87).

\section{Weekly Quarter SCC}

Least squares means QSCC during the FUP were $6.1 \pm 0.1,6.3 \pm 0.1$, and $6.0 \pm 0.1 \log _{10} \mathrm{SCC}$ for cases in the negative control, 2-d IMM, and 8-d IMM group, respectively. Experimental group was not associated with weekly QSCC $(P=0.111$; Figure 4$)$. Time $(P=$ $0.002)$, BC $(P<0.001)$, previous SCM $(P=0.017)$, or severity of $\mathrm{CM}(P=0.016)$ were associated with weekly QSCC. However, interactions between experimental group and previous SCM $(P=0.006)$ were associated with weekly QSCC. Weekly QSCC were greater in cows with previous SCM $\left(6.3 \pm 0.1 \log _{10} \mathrm{SCC}\right)$ compared with cows with no history of SCM $\left(6.0 \pm 0.1 \log _{10} \mathrm{SCC}\right)$,

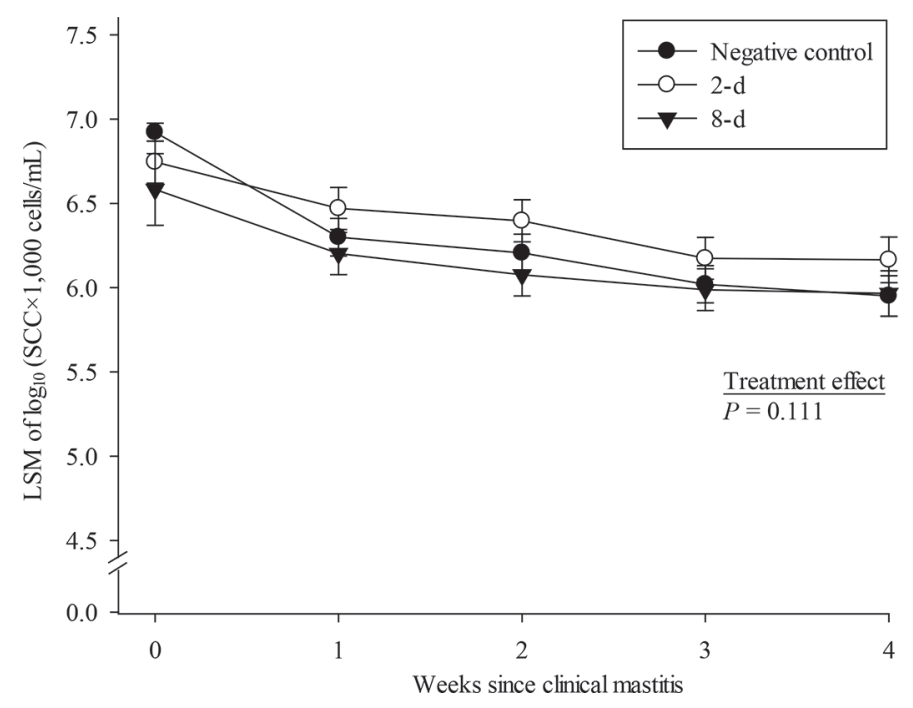

Figure 4. Least squares means of weekly quarter SCC. Negative control $(\mathrm{n}=32), 2$-d intramammary (IMM) ceftiofur $(\mathrm{n}=26)$, and 8 -d IMM ceftiofur $(\mathrm{n}=27)$. Repeated-measures analysis included the effect of treatments, time, severity of clinical mastitis, previous subclinical mastitis, and bacteriological cure at 14 and $21 \mathrm{~d}$ after case detection. The SEM are depicted for LSM of weekly quarter SCC. 
and in cows with moderate cases of $\mathrm{CM}(6.3 \pm 0.1$ $\left.\log _{10} \mathrm{SCC}\right)$ compared with cows with mild CM $(6.0 \pm$ $\left.0.1 \log _{10} \mathrm{SCC}\right)$. Cases that experienced BC $(5.9 \pm 0.1$ $\log _{10} \mathrm{SCC}$ ) had lower QSCC compared with cases that did not experience $\mathrm{BC}\left(6.4 \pm 0.1 \log _{10} \mathrm{SCC}\right)$.

\section{Daily Milk Production}

Least squares means of daily milk production during the FUP were $37.1 \pm 1.5,36.3 \pm 1.4$, and $37.6 \pm 1.5$ $\mathrm{kg} / \mathrm{cow}$ per day for cows in the negative control, $2-\mathrm{d}$, and 8-d group, respectively. Experimental group was not associated with differences in daily milk production $(P=0.589$; Figure 5$)$. Time $(P<0.001)$, parity group $(P=0.041)$, voluntary quarter dry-off $(P=0.021)$, DIM $(P<0.001)$, average daily milk yield 1 to $7 \mathrm{~d}$ before case detection $(P<0.001)$, and the interaction between experimental group and time $(P=0.023)$ were all associated with daily milk production. Primiparous cows produced $35.7 \pm 1.6 \mathrm{~kg} /$ cow, compared with 38.3 $\pm 1.2 \mathrm{~kg} /$ cow for multiparous cows. Cows with a quarter voluntarily dried off during FUP $(35.7 \pm 1.5 \mathrm{~kg} /$ cow) produced less milk than cows without a quarter voluntarily dried off $(38.3 \pm 1.3 \mathrm{~kg} / \mathrm{cow})$.

\section{DISCUSSION}

Participating herds used milking routines and management practices similar to large conventional dairy farms in Wisconsin (Rowbotham and Ruegg, 2015), and milk production and SCC were characteristic of large herds housed in the same region using freestalls bedded with manure solids (Pinzón-Sánchez and Ruegg, 2011; Fuenzalida et al., 2015; Rowbotham and Ruegg, 2015). Although the herds had the same owner, demographic characteristics, milk production, SCC, and characteristics of $\mathrm{CM}$ varied between farms. Compared with farm A, farm B contained more primiparous cows, had lower milk production, higher individual $\log _{10} \mathrm{SCC}$, and greater incidence of CM. Of total cases of CM, small differences existed in the proportion categorized as mild, although no differences were observed for severe cases. More than $90 \%$ of cases occurred in a single quarter, but we observed small differences between farms. Of CM cases enrolled, more than $90 \%$ of mild cases were detected in farm A, as opposed to $60 \%$ in farm $\mathrm{B}$, but after randomization, each experimental group had similar proportions of mild and moderate cases. Overall, distribution of severity of all CM cases agreed with Oliveira et al. (2013). Some moderate cases of CM enrolled in the study received fluid therapy, but this treatment was not associated with any outcomes (data not shown). Although the 2 farms had the same owner and followed similar management practices, they had

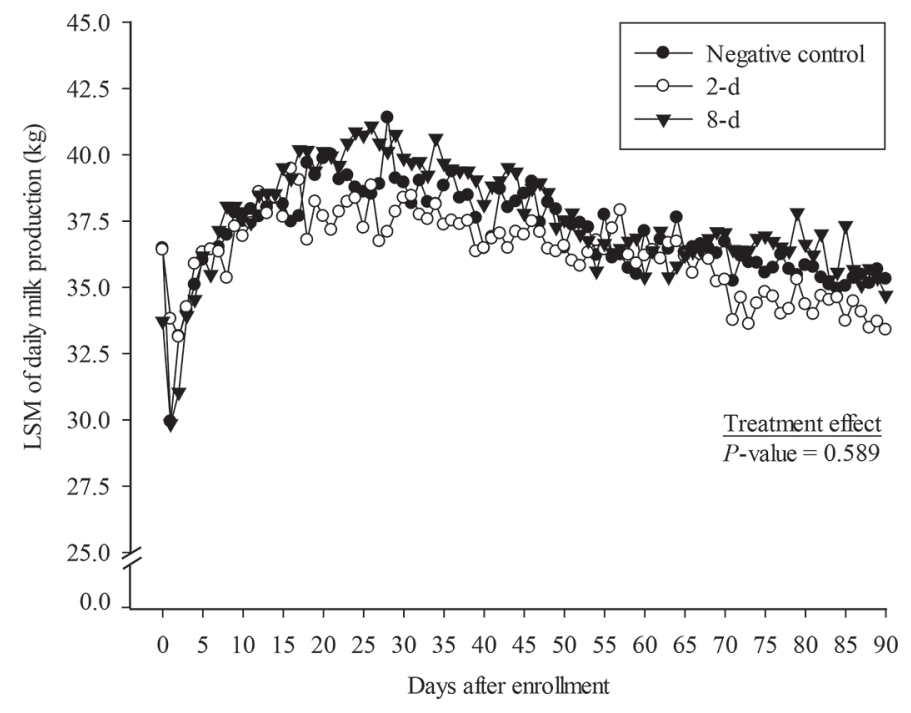

Figure 5. Least squares means of daily milk production. Negative control $(\mathrm{n}=46), 2$-d intramammary (IMM) ceftiofur $(\mathrm{n}=48)$, and 8 -d IMM ceftiofur $(\mathrm{n}=50)$ groups. Repeated-measures analysis included the effect of treatments, time, parity group, DIM, average milk production 1 to $7 \mathrm{~d}$ before case detection, and voluntary quarter dry-off.

different herd managers, and we observed differences between farms that influenced production, milk quality, and incidence of mastitis. It is unlikely that those differences biased results of this study, as randomization occurred within each farm.

We designed this study as a superiority trial, as indicated by inclusion of a negative control group (Mallat, 2017). We hypothesized that IMM treatment using ceftiofur ( 2 or $8 \mathrm{~d}$ ) would have outcomes superior to those of cases in the negative control group. Sample size per experimental group was similar to a previously published negatively controlled randomized clinical trial for gram-negative mastitis; however, our study included fewer farms and did not include cases caused by Enterobacter spp. (Schukken et al., 2011). Unfortunately, blinding was not possible because our objective was to compare outcomes of cows that received 2- or 8-d IMM treatment with outcomes of cows that did not receive any treatments. Furthermore, farm workers needed to be aware of which cows received antibiotics to follow appropriate withholding periods for milk and meat.

In general, CM caused by gram-negative bacteria occur as approximately one-third mild, one-third moderate, and one-third severe (Oliveira et al., 2013). For cases of CM caused by gram-negative bacteria, antimicrobial treatments usually vary based on severity, with most mild and moderate cases treated solely with IMM antibiotics and most severe cases receiving both IMM treatment and additional secondary treatments (Oliveira and Ruegg, 2014). For nonsevere cases of CM, 
several researchers have recommended culture-based, selective treatment programs that use antimicrobials for gram-positive cases but withhold antibiotics to allow for spontaneous cure of gram-negative cases; following these protocols has been shown to result in reduced antimicrobial usage and lower costs associated with treatment of CM (Lago et al., 2011a,b; Pinzón-Sánchez et al., 2011; Ruegg, 2017; Vasquez et al., 2017). Although a considerable body of research supports withholding antibiotics for nonsevere cases of CM caused by gramnegative bacteria, differences in clinical outcomes based on type of gram-negative bacteria merit consideration when designing treatment protocols (Todhunter et al., 1991; Schukken et al., 2011; Oliveira and Ruegg, 2014). In the United States, ceftiofur is 1 of 2 IMM antimicrobials labeled for treatment of mastitis caused by gram-negative bacteria and is the most commonly used IMM antimicrobial overall (USDA, 2014; Ruegg, 2017). Although the World Health Organization (WHO, 2017) has categorized ceftiofur as high priority and critically important for human health, we selected this treatment because of its wide usage and FDA-approved labeling that allows for variable duration of treatment, and because it was the standard treatment used on the farms that were enrolled in this study.

In the United States, the majority of cases of nonsevere CM receive only IMM infusion of antimicrobials, but extralabel treatments using systemic antimicrobials and other supportive therapies are allowed under veterinary supervision and are sometimes administered (Oliveira and Ruegg, 2014). In other countries, use of meloxicam and other nonsteroidal anti-inflammatories have been shown to be beneficial for alleviating pain and other clinical signs of mastitis (Banting et al., 2008; Fitzpatrick et al., 2013) but flunixin meglumine is the only nonsteroidal anti-inflammatory approved to treat lactating dairy cows in the United States. Mastitis can be a painful disease, and, where approved, use of nonsteroidal anti-inflammatories and other products to relieve pain should be considered (Leslie and PeterssonWolfe, 2012).

Cows on both farms were housed in stalls containing deep-bedded manure solids that are known to be a source of teat-end exposure to both E. coli and Klebsiella spp. (Rowbotham and Ruegg, 2016). Although previous research has shown that culture-based systems can only accurately differentiate gram-positive from gram-negative bacteria (Royster et al., 2014), before the study began, veterinarians and managers employed on both farms commonly used OFC to guide mastitis treatment decisions, and at the beginning of the study, they were confident in their ability to differentiate $E$. coli from Klebsiella spp. Our results indicated that differentiation of E. coli from Klebsiella spp. based on
OFC was not sufficiently accurate to guide pathogenbased treatment decisions. The importance of differentiating between E. coli and Klebsiella spp. is based on different effects on production and health of affected cows. Todhunter and colleagues (1991) observed that IMI caused by Klebsiella spp. $(124.4 \pm 20.1 \mathrm{~d})$ were of much longer duration than IMI caused by E. coli $(23.6 \pm 7.7 \mathrm{~d})$. Milk production loss has been demonstrated to be much greater in cases of CM caused by Klebsiella spp. compared with E. coli (Gröhn et al., 2004), as is the risk of culling (Gröhn et al., 2005). In our study, negative outcomes such as risk of voluntary dry-off and culling were exacerbated when Klebsiella spp. caused CM, and positive outcomes such as BC decreased for cases caused by Klebsiella spp. compared to cases caused by E. coli. Development of accurate on-farm methods to differentiate among gram-negative pathogens are needed, to allow farmers to better guide treatment decisions.

Clinical cure is widely used by farmers and researchers as a visual indication of success of IMM therapy. However, several observational studies (Hoe and Ruegg, 2005; Oliveira and Ruegg, 2014) and a randomized clinical trial (Fuenzalida and Ruegg, 2019) have demonstrated that clinical cure is not an objective determinant of treatment efficacy. In our study, 2-d or 8-d IMM treatment with ceftiofur was not associated with days to clinical cure or with the proportion of cases experiencing clinical cure within $10 \mathrm{~d}$ after enrollment. Similar to our previous study (Fuenzalida and Ruegg, 2019), clinical cure occurred about $4 \mathrm{~d}$ after enrollment. Regardless of treatment, the majority of quarters experienced clinical cure by $\mathrm{d} 7$, and farmers should be advised to wait at least $8 \mathrm{~d}$ before making any decision about re-treatment. Interestingly, the inflammatory process does not seem to vary depending on pathogen and is not predictive of important clinical outcomes such as future milk yield, SCC, recurrence of $\mathrm{CM}$, or culling risk. Our work clearly indicates that observations of clinical cure should not be used to define efficacy of mastitis therapies.

Achieving bacteriological clearance is the goal of antimicrobial therapy, and $\mathrm{BC}$ is an objective measurement commonly used to define efficacy of antimicrobial treatments. Previous researchers have not recommended antimicrobial treatment of $\mathrm{CM}$ caused by gramnegative bacteria, especially E. coli, because $\mathrm{BC}$ rates were not improved with such treatment (Pyörälä et al., 1994; Pyörälä and Pyörälä, 1998; Suojala et al., 2010). Our overall results indicated that $66 \%$ of enrolled cases experienced $\mathrm{BC}$ within $21 \mathrm{~d}$ after enrollment, and $\mathrm{BC}$ was greater in quarters that received IMM ceftiofur. We observed that the probability of $\mathrm{BC}$ after $21 \mathrm{~d}$ of enrollment progressively increased for cases that received 
IMM ceftiofur versus the negative control group. Bacteriological cure of quarters that received IMM ceftiofur were similar to those described for gram-negative bacteria by Suojala et al. (2010) and Oliveira et al. (2013) and were considerably greater than those reported by Schukken et al. (2011). However, Schukken et al. (2011) defined $\mathrm{BC}$ based on milk obtained at 7 and $14 \mathrm{~d}$ after the last treatment, and when samples were missing, the cases were categorized as bacteriological failure, biasing results toward greater proportion of bacteriological failures.

The formulation of ceftiofur hydrochloride that is approved in the United States for IMM treatment of mastitis is not labeled for treatment of Klebsiella spp. but does contain a label claim for E. coli. Although IMM ceftiofur treatment had a positive effect on BC, our results indicated that the type of gram-negative pathogen causing CM confounded the treatment effect on BC. Overall, we observed differing effects of IMM ceftiofur treatment depending on whether $E$. coli or Kleb. pneumoniae caused CM, and when pathogen was considered, IMM ceftiofur treatment (2-d or 8-d) improved $\mathrm{BC}$ only for cases caused by Kleb. pneumoniae. Bacteriological cure of $\mathrm{CM}$ caused by $E$. coli was very high (ranging from 93 to 100\%) and was not associated with IMM treatment. Escherichia coli was rarely isolated from quarters after enrollment, indicating that IMI caused by E. coli was of short duration. Although Kleb. pneumoniae was isolated in a small proportion of milk samples collected from 14 to $28 \mathrm{~d}$ after enrollment, these organisms were consistently recovered from some milk samples, indicating development of chronic IMI in some quarters. Our results indicated that in vitro ceftiofur susceptibility also differed depending on type of gram-negative bacteria. For E. coli, almost $100 \%$ of isolates were susceptible to ceftiofur. Klebsiella pneumoniae isolates followed a bimodal distribution for antimicrobial susceptibility; thus, some isolates with high MIC represented a high proportion of the population (Watts and Lindeman, 2006). For CM cases caused by Kleb. pneumoniae, BC, risk of culling, and voluntary quarter dry-off differed depending on ceftiofur susceptibility. Previous reports (Hoe and Ruegg, 2005) showed no association between antimicrobial susceptibility and $\mathrm{BC}$, though the association was studied between pirlimycin and different etiologies. When phenotypic characteristics are used to differentiate among gramnegative bacteria (such as in OFC), it is likely that Klebsiella spp. are overdiagnosed. Based on previous studies in our laboratory, $<10 \%$ of $\mathrm{CM}$ cases on large confinement dairy farms in Wisconsin are caused by Klebsiella spp. (Oliveira et al., 2013). Clinical and bacteriological outcomes of nonsevere gram-negative mastitis were different among cases caused by Kleb. pneumoniae and E. coli, and our data suggests that additional research to define appropriate treatment of cases caused by Kleb. pneumoniae is needed.

Overall, similar to results of Schukken et al. (2011) for mastitis caused by coliforms, neither $2 \mathrm{~d}$ nor $8 \mathrm{~d}$ of IMM therapy was associated with improvements in economically relevant outcomes such as milk production, QSCC, or risk of culling. When Kleb. pneumoniae was the etiology, the risks of culling and voluntary quarter dry-off were increased, but the probability of bacterial clearance during the FUP decreased. Although it is important to encourage farmers to focus on reducing teat-end exposure to pathogens such as Klebsiella spp., need remains for research to identify additional diagnostic methods that allow rapid differentiation between Klebsiella spp. and other gram-negative bacteria, to better target therapies.

Milk production is an economically relevant outcome that needs to be assessed to evaluate the cost-effectiveness of mastitis treatments. Based on a decision tree model that included costs, benefits, and probabilities associated with potential outcomes after treatment of nonsevere, gram-negative CM, the greatest expected monetary value was observed for no treatment rather than for 2- or 8-d IMM ceftiofur treatment (PinzónSánchez et al., 2011). Results of our study support the assumptions of this model, as use of 2-d or 8-d IMM ceftiofur treatment of gram-negative cases did not improve daily milk production during the 90-d FUP but did extend duration of milk discard. Compared with nontreated cows, use of 2-d IMM treatment resulted in a 1-d increase in milk discard, and use of 8-d treatment resulted in 6 additional days of milk discard. Both herds produced about $36 \mathrm{~kg}$ of milk/cow per day, and for cows receiving 8-d IMM antibiotic about $396 \mathrm{~kg}$ of milk $(36 \mathrm{~kg} \times 11 \mathrm{~d})$ was discarded, for $\$ 143$ in lost milk income (milk price $\$ 0.36 / \mathrm{kg}$ ). Clinical mastitis caused by gram-negative bacteria was detrimental with regard to milk yield, SCC, and culling, but IMM treatment did not improve any of these outcomes. Based on our results, use of antibiotics for treatment of nonsevere CM caused by gram-negative bacteria results in increased costs without apparent benefit in key clinical outcomes.

Compared with healthy cows, occurrence of CM is associated with increased risk of culling (Pinzón-Sánchez et al., 2011), although etiology has a large effect (Gröhn et al., 2005). In a previous study, we demonstrated that nonsevere CM caused by culture-negative pathogens was associated with infrequent occurrence of culling (Fuenzalida and Ruegg, 2019), but we observed that overall risk of culling was greater for cows affected with gram-negative mastitis. Overall, $14 \%$ of cows enrolled in our study were culled during the FUP, and etiology (but not IMM ceftiofur treatment) influenced 
this outcome. Of cows with CM caused by E. coli, $7 \%$ were culled; in contrast, $22 \%$ of cows with CM caused by Kleb. pneumoniae were culled, which is consistent with previous reports (Gröhn et al., 2005). In addition to culling, veterinarians on these herds used a standard protocol to routinely dry off quarters of cows. Voluntary dry-off of quarters is a common practice in some US herds, and use of manure solids has shown to be associated with a higher proportion of cows that are milking on $<4$ quarters (Rowbotham and Ruegg, 2015). This practice was used for cows enrolled in our study. Of quarters enrolled in our study, $25 \%$ were voluntarily dried off, and this proportion was not improved by use of IMM ceftiofur. However, quarters with CM caused by Kleb. pneumoniae were more likely to be dried off than quarters with CM caused by E. coli. When manure solids are used for bedding, cows experience increased exposure to Klebsiella spp. (Rowbotham and Ruegg, 2016), and these cows are at increased risk for loss of affected quarters and premature culling. These additional risks should be considered when farmers make decisions about bedding types.

Quarter SCC represents an objective measurement of the inflammatory response after IMI. Based on our data, use of either 2-d or 8-d IMM ceftiofur did not result in reduced QSCC during our 28-d FUP. This outcomes agrees with results of our previous trial that enrolled culture-negative cases (Fuenzalida and Ruegg, 2019) and with previous research of CM caused by gram-negative (Schukken et al., 2011) and grampositive (Oliver et al., 2004) pathogens. The patterns we observed for QSCC indicate that the inflammatory response varies depending on characteristics of the host (i.e., occurrence of previous SCM and severity of CM) and the pathogen. Mild cases that experienced $\mathrm{BC}$ and had no previous SCM had lower QSCC during the FUP. These results agree with Schukken et al. (2011), as SCC were lower in cases that experienced $\mathrm{BC}$ compared with those that did not experience BC.

Recurrence of $\mathrm{CM}$ is a costly sequela of $\mathrm{CM}$ that results in reduced milk production and increased risk of culling (Pinzón-Sánchez et al., 2011; Jamali et al., 2018) and thus has considerable negative economic impact. In contrast to infrequent recurrence of $\mathrm{CM}$ in culture-negative cases (Fuenzalida and Ruegg, 2019), in cases of gram-positive infection, CM recurred frequently. However, use of 2-d or 8-d IMM treatment with ceftiofur did not reduce the probability of QREC. In agreement with previous studies (Jamali et al., 2018; Fuenzalida and Ruegg, 2019), host factors such as older parity group and increased SCC before occurrence of CM increased the probability of QREC. Based on our results, we recommend that farmers should review the clinical history of the cow and parity group to determine whether a cow is a good candidate for antimicrobial therapy; ideally, first-lactation cows without history of SCM might benefit most from antimicrobial therapy.

Based on common use of voluntary quarter dry-off, we were able to compare milk production of cows with and without 4 functional mammary glands. In the cows we enrolled, daily milk production was approximately 3 $\mathrm{kg}$ greater for cows with all 4 functional quarters during FUP than for cows with only 3 functional quarters. The high prevalence of nonsevere mastitis caused by Kleb. pneumoniae is likely associated with this outcome. These herds used bacterin core-antigen vaccines intended to reduce mastitis due to E. coli, and the recent introduction of Klebsiella-specific mastitis vaccines in the United States suggests a need to investigate the effects of immunization on the frequency of these costly negative outcomes. Gorden et al. (2018) reported that a Kleb. pneumoniae siderophore receptor protein vaccine increased milk production by $1.74 \mathrm{~kg} / \mathrm{d}$ and reduced SCC by $64.8 \%$ in one herd when cows were vaccinated before calving, compared with cows that did not receive the vaccine. Nonetheless, the vaccine did not reduce the risk of mastitis; thus, further research is needed to study the effects of this vaccine at a multi-herd level.

Compared with clinical outcomes of culture-negative, nonsevere CM (Fuenzalida and Ruegg, 2019), detrimental clinical outcomes (QREC and culling) occurred more frequently in cases caused by gram-negative bacteria. Prior to the study, sample size estimates were based on data from previous studies (Schukken et al., 2011; Oliveira et al., 2013), and our final sample size per experimental group was similar to that of Schukken et al. (2011). However, we observed much smaller differences among experimental groups than predicted. For BC we observed differences of $20 \%$ between treated cases and nontreated cases, whereas Schukken et al. (2011) described differences of approximately $60 \%$. Based on the small differences we observed, we did not have sufficient power to find differences for QREC, but for BC, we observed differences between use of 8-d IMM treatment and the negative control group. However, differences in $\mathrm{BC}$ were mostly pathogen-driven, because the probability of $\mathrm{BC}$ was greater for CM caused by $E$. coli than for CM caused by Kleb. pneumoniae. For CM caused by $E$. coli, BC was greater than $90 \%$ regardless of experimental group. In contrast, we observed 13 times greater probability of $\mathrm{BC}$ for CM caused by Kleb. pneumoniae and treated with IMM ceftiofur compared with those not treated. The lack of biological relevance of these small differences is evident in that we would have needed to enroll 22,477 cases per experimental group to detect differences between all binomial outcomes. A mastitis study of this scale is virtually impossible and would have questionable economic relevance. 
Although we did not demonstrate that use of IMM ceftiofur for treatment of nonsevere CM improved clinical outcomes, we did observe differences in outcomes between CM caused by E. coli versus Kleb. pneumoniae. The odds of culling cows affected with CM caused by Kleb. pneumoniae were almost 3 times greater than for cases caused by E. coli. Bacteriological cure rates were greater for cases caused by E. coli compared with cases caused by Kleb. pneumoniae. We have demonstrated that IMM ceftiofur treatment of nonsevere E. coli $\mathrm{CM}$ does not have an economic effect and cannot be recommended for most nonsevere cases. Based on our results we would not recommend use of IMM ceftiofur treatment for nonsevere cases of CM caused by E. coli, because the immune response of the cow is able to deal successfully with the infection and subsequent inflammation caused by this bacterium. However, it is important to consider that using OFC to improve treatment decision can only help when we want to differentiate between gram-positive and gram-negative bacteria. In this study, when farmers used OFC to differentiate between E. coli and Kleb. pneumoniae, the discriminatory power was not greater than $50 \%$. Commercial tests are available to differentiate between Klebsiella spp. from $E$. coli, but that option should only be used when the prevalence of CM caused by Klebsiella spp. is higher than expected (>7\%, Oliveira et al., 2013) and the clinical history of those cases reflect the type of infection caused by that bacterium. When it is worthwhile to differentiate between gram-negative pathogens, we would recommend 8-d IMM treatment for primiparous cows with a first case of CM caused by Klebsiella spp. because the prognosis of those cases is better than that of cases where a chronic inflammation has been already established within the mammary gland and most likely that infection might be accompanied by recurrent cases of CM.

From the perspective of a dairy farmer, use of IMM antimicrobials should result in improved clinical outcomes that are associated with improved profitability and cow welfare. Based on our results, the effect of IMM ceftiofur treatment was confounded by whether CM was caused by E. coli or Kleb. pneumoniae. Intramammary ceftiofur treatment was negatively associated with days of milk discard and positively associated with $\mathrm{BC}$, but this last outcome was confounded by the effect of the type of gram-negative bacterium causing CM $(E$. coli or Kleb. pneumoniae). The economic effects of these outcomes can be estimated for nonsevere, gram-negative CM. For example, based on typical distribution of pathogens (Oliveira et al., 2013), a 3,000-cow farm with a $40 \%$ incidence of CM would experience 300 cases of gram-negative CM per year ( $25 \%$ of all CM). Although we did not observe statistically significant differences in
QREC, compared with cases that received $8 \mathrm{~d}$ of IMM ceftiofur, cows that did not receive antibiotics would have 81 additional cases that did not achieve $\mathrm{BC}$ and would also have 5.5 additional days of discarded milk per case $(1,650 \mathrm{~d})$. No benefits of $8 \mathrm{~d}$ of IMM ceftiofur would be expected for daily milk production, risk of culling, or QSCC. If the herd averaged $36 \mathrm{~kg}$ of milk/d, the additional days of discarded milk would equal $59,400 \mathrm{~kg}$ of milk at a value of $\$ 21,384(\$ 0.36 / \mathrm{kg})$, without considering costs of treatment [about $\$ 10,800$ for purchase of $8-d$ IMM treatment ( $\$ 4.50$ per tube)]. Our results suggest no economic benefit of IMM ceftiofur treatment for nonsevere, gram-negative CM cases, but further research would establish the cost-benefit of not treating all these cases, as different outcomes are expected depending on the type of gram-negative pathogen causing CM.

We calculated NNT for BC. Clearly, smaller NNT indicates a greater value of IMM treatment, but none of these outcomes represents cost-effective strategies. Ceftiofur is a third-generation cephalosporin and is classified by the World Health Organization as a critically important antimicrobial (WHO, 2017). Ceftiofur should be reserved for cases that will not respond to alternative therapies. Although it is important to ensure that CM treatments are designed to promote cow welfare, no studies currently indicate that use of critically important antimicrobials for treatment of nonsevere cases of gram-negative mastitis achieve this aim. Managers of modern dairy farms must focus on prevention of exposure to gram-negative pathogens and develop rational treatment protocols that limit use of antimicrobials to cases that will not respond satisfactorily to alternative strategies. Our results indicate that reduction of antimicrobial usage is possible when OFC is used to guide treatment decisions of nonsevere gram-negative $\mathrm{CM}$ but that discrimination among gram-negative bacteria is not satisfactory. We observed that the effect of IMM treatment on several clinical outcomes is driven by type of pathogen causing $\mathrm{CM}$ cases and, from that point of view, recommend use of specific tests to differentiate between E. coli and Kleb. pneumoniae when antibiotic therapy is considered.

\section{CONCLUSIONS}

Intramammary treatment using 2-d or 8-d ceftiofur did not reduce quarter recurrence of CM, culling, days to clinical cure, voluntary dry-off of affected quarters, post-treatment SCC of affected quarters, or daily milk yield during a 90-d follow-up period. Use of IMM ceftiofur resulted in increased $\mathrm{BC}$ and increased number of days of discarded milk but did not result in improved daily milk production, reduced culling, or improvements 
in SCC. We did not demonstrate that IMM treatment improved clinical outcomes, but we observed differences in outcomes between cases caused by E. coli and Kleb. pneumoniae. The effect of IMM ceftiofur on BC was pathogen driven, and regardless of treatment, almost all cases of CM caused by E. coli resulted in rapid BC. In contrast, IMM ceftiofur treatment improved $\mathrm{BC}$ of cases of CM caused by Kleb. pneumoniae. Based on the prevalence of CM caused by Kleb. pneumoniae and the clinical history of affected cows, it is important to distinguish between gram-negative bacteria causing $\mathrm{CM}$, because the risk of culling and voluntary quarter dry-off were greater for cases of CM caused by Kleb. pneumoniae.

\section{ACKNOWLEDGMENTS}

We thank Stephanie Metzger and Eric Gosselin from the Dairy Science Department, University of Wisconsin-Madison, as well as Austin Prichard and Erin Kiehnau from the Veterinary School of the University of Wisconsin-Madison, for helping to conduct this trial. This research was supported by Hatch Act Formula Fund Grant no. WIS01799. The SpectramastLC was donated by Zoetis (Parsippany, NJ).

\section{REFERENCES}

Altman, D. G., and P. K. Andersen. 1999. Calculating the number needed to treat for trials where the outcome is time to an event. BMJ 319:1492-1495.

Bannerman, D. D., M. J. Paape, W. R. Hare, and J. C. Hope. 2004b. Characterization of the bovine innate immune response to intramammary infection with Klebsiella pneumoniae. J. Dairy Sci. $87: 2420-2432$.

Bannerman, D. D., M. J. Paape, J. W. Lee, X. Zhao, J. C. Hope, and P. Rainard. 2004a. Escherichia coli and Staphylococcus aureus elicit differential innate immune responses following intramammary infection. Clin. Diagn. Lab. Immunol. 11:463-472.

Banting, A., S. Banting, K. Heinonen, and K. Mustonen. 2008. Efficacy of oral and parenteral ketoprofen in lactating cows with endotoxin-induced acute mastitis. Vet. Rec. 163:506-509.

CLSI (Clinical and Laboratory Standards Institute). 2013. Performance standards for antimicrobial disk and dilution susceptibility tests for bacteria isolated from animals; Approved standard. VET01. 4th ed. CLSI, Wayne, PA.

CLSI (Clinical and Laboratory Standards Institute). 2015. Performance standards for antimicrobial disk and dilution susceptibility tests for bacteria isolated from animals. VET01S. 3rd ed. CLSI, Wayne, PA.

Cohen, J. A. 1960. A coefficient of agreement for nominal scales. Educ. Psychol. Meas. 20:37-46.

Erskine, R. J., R. D. Walker, C. A. Bolin, P. C. Bartlett, and D. G. White. 2002. Trends in antibacterial susceptibility of mastitis pathogens during a seven-year period. J. Dairy Sci. 85:1111-1118.

Fitzpatrick, C. E., N. Chapinal, C. S. Petersson-Wolfe, T. J. DeVries, D. F. Kelton, T. F. Duffield, and K. E. Leslie. 2013. The effect of meloxicam on pain sensitivity, rumination time, and clinical signs in dairy cows with endotoxin-induced clinical mastitis. J. Dairy Sci. 96:2847-2856.

Fuenzalida, M. J., P. M. Fricke, and P. L. Ruegg. 2015. The association between occurrence and severity of subclinical and clinical mastitis on pregnancies per artificial insemination at first service of Holstein cows. J. Dairy Sci. 98:3791-3805.

Fuenzalida, M. J., and P. L. Ruegg. 2019. Negatively controlled, randomized clinical trial to evaluate use of intramammary ceftiofur for treatment of nonsevere culture-negative clinical mastitis. J. Dairy Sci. 102:3321-3338. https://doi.org/10.3168/jds.2018-15497.

Gorden, P. J., M. D. Kleinhenz, J. A. Ydstie, T. A. Brick, L. M. Slinden, M. P. Peterson, D. E. Straub, and D. T. Burkhardt. 2018. Efficacy of vaccination with Klebsiella pneumoniae siderophore receptor protein vaccine for reduction of Klebsiella mastitis in lactating cattle. J. Dairy Sci. 101:10398-10408.

Gröhn, Y. T., R. N. González, D. J. Wilson, J. A. Hertl, G. Bennett, H. Schulte, and Y. H. Schukken. 2005. Effect of pathogen-specific clinical mastitis on herd life in two New York State dairy herds. Prev. Vet. Med. 71:105-125.

Gröhn, Y. T., D. J. Wilson, R. N. González, J. A. Hertl, H. Schulte, G. Bennett, and Y. H. Schukken. 2004. Effect of pathogen-specific clinical mastitis on milk yield in dairy cows. J. Dairy Sci. 87:3358-3374.

Hoe, F. G. H., and P. L. Ruegg. 2005. Relationship between antimicrobial susceptibility of clinical mastitis pathogens and treatment outcomes in cows. J. Am. Vet. Med. Assoc. 227:1461-1468.

Jamali, H., H. W. Barkema, M. Jacques, E. Lavallée-Bourget, F. Malouin, V. Saini, H. Stryhn, and S. Dufour. 2018. Invited review: Incidence, risk factors, and effects of clinical mastitis recurrence in dairy cows. J. Dairy Sci. 101:4729-4746.

Lago, A., S. M. Godden, R. Bey, P. L. Ruegg, and K. Leslie. 2011a. The selective treatment of clinical mastitis based in on-farm culture results: I. Effects on antibiotic use, milk withholding time, and short-term clinical and bacteriological outcomes. J. Dairy Sci. 94:4441-4456.

Lago, A., S. M. Godden, R. Bey, P. L. Ruegg, and K. Leslie. 2011b. The selective treatment of clinical mastitis based in on-farm culture results: I. Effects on lactation performance, including clinical mastitis recurrence, somatic cell count, milk production, and cow survival. J. Dairy Sci. 94:4457-4467.

Lavon, Y., E. Ezra, G. Leitner, and D. Wolfenson. 2011. Association of conception rate with pattern and level of somatic cell count elevation relative to time of insemination in dairy cows. J. Dairy Sci. 94:4538-4545.

Leslie, K. E., and C. S. Petersson-Wolfe. 2012. Assessment and management of pain in dairy cows with clinical mastitis. Vet. Clin. North Am. Food Anim. Pract. 28:289-305.

Makovec, J. A., and P. L. Ruegg. 2003. Antimicrobial resistance of bacteria isolated from dairy cow milk samples submitted for bacterial culture: 8,905 samples (1994-2001). J. Am. Vet. Med. Assoc. 222:1582-1589.

Mallat, J. 2017. Understanding the null hypothesis $\left(\mathrm{H}_{0}\right)$ in non-inferiority trials. Crit. Care 21:101.

National Mastitis Council. 1999. Laboratory Handbook on Bovine Mastitis. Rev. ed. National Mastitis Council, Verona, WI.

National Mastitis Council. 2017. Laboratory Handbook on Bovine Mastitis. 3rd ed. National Mastitis Council, Madison, WI.

Nobrega, D. B., J. De Buck, and H. W. Barkema. 2018. Antimicrobial resistance in non-aureus staphylococci isolated from milk is associated with systemic but not intramammary administration of antimicrobials in dairy cattle. J. Dairy Sci. 101:7425-7436.

Oliveira, L., C. Hulland, and P. L. Ruegg. 2013. Characterization of clinical mastitis occurring in cows on 50 large dairy herds in Wisconsin. J. Dairy Sci. 96:7538-7549.

Oliveira, L., and P. L. Ruegg. 2014. Treatments of clinical mastitis occurring in cows on 51 large dairy herds in Wisconsin. J. Dairy Sci. 97:5426-5436.

Oliver, S. P., R. A. Almeida, B. E. Gillespie, S. J. Headrick, H. H. Dowlen, D. L. Johnson, K. C. Lamar, S. T. Chester, and W. M Moseley. 2004. Extended ceftiofur therapy for treatment of experimentally-induced Streptococcus uberis mastitis in lactating dairy cattle. J. Dairy Sci. 87:3322-3329.

Pinzón-Sánchez, C., V. E. Cabrera, and P. L. Ruegg. 2011. Decision tree analysis of treatment strategies for mild and moderate cas- 
es of clinical mastitis occurring in early lactation. J. Dairy Sci. 94:1873-1892.

Pinzón-Sánchez, C., and P. L. Ruegg. 2011. Risk factors associated with short-term post-treatment outcomes of clinical mastitis. J. Dairy Sci. 94:3397-3410.

Pyörälä, S., L. Kaartinen, H. Käck, and V. Rainio. 1994. Efficacy of two therapy regimens for treatment of experimentally induced Escherichia coli mastitis in cows. J. Dairy Sci. 77:453-461.

Pyörälä, S. H. K., and E. O. Pyörälä. 1998. Efficacy of parenteral administration of three antimicrobial agents in treatment of clinical mastitis in lactating cows: 487 cases (1989-1995). J. Am. Vet. Med. Assoc. 212:407-412.

Rowbotham, R. F., and P. L. Ruegg. 2015. Association of bedding types with management practices and indicators of milk quality on larger Wisconsin dairy farms. J. Dairy Sci. 98:7865-7885.

Rowbotham, R. F., and P. L. Ruegg. 2016. Bacterial counts on teat skin and in new sand, recycled sand, and recycled manure solids used as bedding in freestalls. J. Dairy Sci. 99:6594-6608.

Royster, E., S. Godden, D. Goulart, A. Dahlke, P. Rapnicki, and J. Timmerman. 2014. Evaluation of the Minnesota Easy Culture System II Bi-Plate and Tri-Plate for identification of common mastitis pathogens in milk. J. Dairy Sci. 97:3648-3659.

Ruegg, P. L. 2017. Practical approaches to mastitis therapy on large dairy herds. Pages 933-948 in Large Dairy Herd Management. 3rd ed. American Dairy Science Association, Champaign, IL.

SAS Institute. 2011. SAS/STAT User's Guide. Version 9.4. SAS Institute Inc., Cary, NC.

Schukken, Y., M. Chuff, P. Moroni, A. Gurjar, C. Santisteban, F. Welcome, and R. Zadoks. 2012. The "other" gram-negative bacteria in mastitis: Klebsiella, serratia, and more. Vet. Clin. North Am. Food Anim. Pract. 28:239-256.

Schukken, Y. H., G. J. Bennett, M. J. Zurakowski, H. L. Sharkey, B. J. Rauch, M. J. Thomas, B. Ceglowski, R. L. Saltman, N. Belomestnykh, and R. N. Zadoks. 2011. Randomized clinical trial to evaluate the efficacy of 5-day ceftiofur hydrochloride intramammary treatment on nonsevere gram-negative clinical mastitis. J. Dairy Sci. 94:6203-6215.
Sifferlin, A. 2017. Here's how to cut antibiotic use in animals. TIME Health. Accessed May 2, 2018. http://time.com/4961051/ antibiotics-animals/.

Smith, K. L., D. A. Todhunter, and P. S. Schoenberger. 1985. Environmental pathogens and intramammary infection during the dry period. J. Dairy Sci. 68:402-417.

Suojala, L., H. Simojoki, K. Mustonen, L. Kaartinen, and S. Pyörälä. 2010. Efficacy of enrofloxacin in the treatment of naturally occurring acute clinical Escherichia coli mastitis. J. Dairy Sci. 93:19601969

Todhunter, D. A., K. L. Smith, J. S. Hogan, and P. S. Schoenberger. 1991. Gram-negative bacterial infections of the mammary gland in cows. Am. J. Vet. Res. 52:184-188.

University of Minnesota Laboratory for Udder Health. 2004. Minnesota Easy Culture System II user's manual. University of Minnesota, Saint Paul, MN.

USDA. 2014. Milk quality, milking procedures, and mastitis on U.S. dairies. USDA-Animal and Plant Health Inspection Service-Veterinary Services, National Animal Health Monitoring System, Riverdale, MD. Accessed Apr. 2, 2018. https://www.aphis.usda .gov/animal_health/nahms/dairy/downloads/dairy14/Dairy14 dr_Mastitis.pdf.

Vasquez, A. K., D. V. Nydam, M. B. Capel, S. Eicker, and P. D. Virkler. 2017. Clinical outcome comparison of immediate blanket treatment versus a delayed pathogen-based treatment protocol for clinical mastitis in a New York dairy herd. J. Dairy Sci 100:2992-3003.

Watts, J. L., and C. J. Lindeman. 2006. Antimicrobial susceptibility testing of bacteria of veterinary origin. Pages 29-35 in Antimicrobial Resistance in Bacteria of Animal Origin. Frank M. Aarestrup, ed. ASM Press, Washington, DC

WHO (World Health Organization). 2017. Critically important for human medicine. 5th revision 2016. Accessed Sep. 7, 2018 http: / apps.RCT.int/iris/bitstream/handle/10665/255027/ 9789241512220-eng.pdf? sequence $=1$. 